\title{
Avoiding Sovereign Default Contagion: A Normative Analysis
}

de Ferra, Sergio and Enrico Mallucci

Please cite paper as:

de Ferra, Sergio and Enrico Mallucci (2020). Avoiding

Sovereign Default Contagion: A Normative Analysis

International Finance Discussion Papers 1275.

https://doi.org/10.17016/IFDP.2020.1275

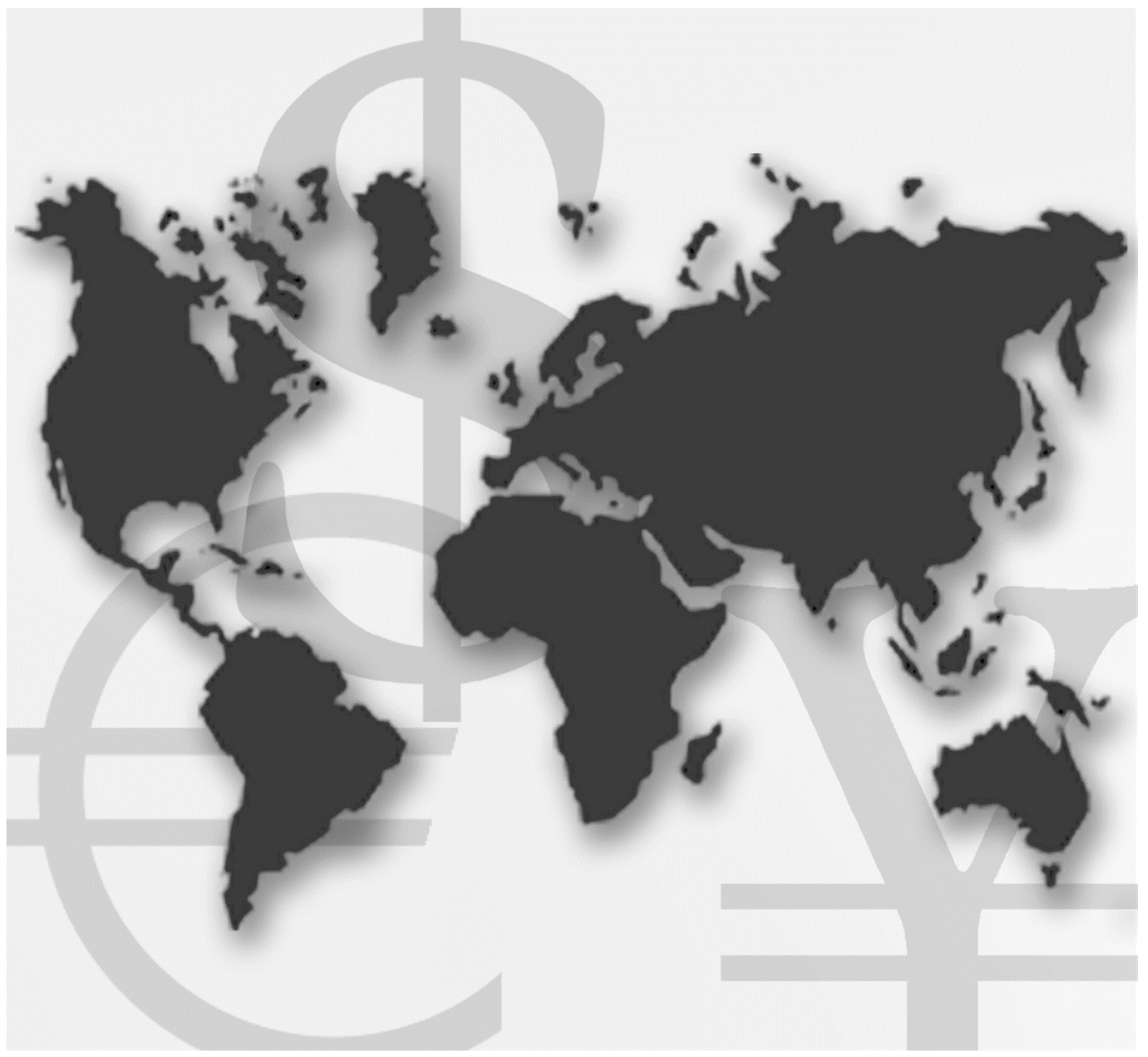

\section{International Finance Discussion Papers}

Board of Governors of the Federal Reserve System

Number 1275

February 2020 
Board of Governors of the Federal Reserve System

International Finance Discussion Papers

Number 1275

February 2020

\section{Avoiding Sovereign Default Contagion: A Normative Analysis}

Sergio de Ferra and Enrico Mallucci

NOTE: International Finance Discussion Papers (IFDPs) are preliminary materials circulated to stimulate discussion and critical comment. The analysis and conclusions set forth are those of the authors and do not indicate concurrence by other members of the research staff or the Board of Governors. References in publications to the International Finance Discussion Papers Series (other than acknowledgement) should be cleared with the author(s) to protect the tentative character of these papers. Recent IFDPs are available on the Web at www.federalreserve.gov/pubs/ifdp/. This paper can be downloaded without charge from the Social Science Research Network electronic library at www.ssrn.com. 


\title{
Avoiding Sovereign Default Contagion: A Normative Analysis*
}

\author{
Sergio de Ferra ${ }^{\dagger} \quad$ Enrico Mallucci ${ }^{\ddagger}$
}

\begin{abstract}
Should debtor countries support each other during sovereign debt crises? We answer this question through the lens of a two-country sovereign-default model that we calibrate to the euro-area periphery. First, we look at cross-country bailouts. We find that whenever agents anticipate their existence, bailouts induce moral hazard an reduce welfare. Second, we look at the borrowing choices of a global central borrower. We find that it borrows less than individual governments and, as such, defaults become less frequent and welfare increases. Finally, we show that central borrower's policies can be replicated in a decentralized setting with Pigouvian taxes on debt.
\end{abstract}

JEL classification: F34, F41, F45, H63

Keywords: Sovereign default, sovereign contagion, bailouts, Pigouvian taxes

*We are especially indebted to Kostas Mavromatis for the fruitful conversations with him at the early stage of the project that got this paper started. We are also very thankful to Tamon Asonuma, Aitor Erce, Bernardo Guimaraes, Sandra Lizarazo, Leonardo Martinez, Fabrizio Perri, and Vivian Yue for comments and suggestions.

†Stockholm University. E-mail: sergio.deferra@ne.su.se.

${ }^{\ddagger}$ Board of Governors of the Federal Reserve System, Washington, D.C. 20551 U.S.A.. E-mail: enrico.mallucci@frb.gov. 


\section{Introduction}

Recent advances in the sovereign default literature have finally began to acknowledge the existence of cross-country contagion in the sovereign debt market: sovereign debt crises happen in waves spreading from one country to the other. The euro-area debt crisis is a neat example of that. Stress in the sovereign debt market quickly spread from Greece and Ireland to Portugal, Spain, and Italy. Following the euro-area debt crisis, an interesting debate has emerged on the desirability of cross-country arrangements aimed at reducing contagion in the sovereign market. On the one side, some have argued that cross-country arrangements are needed to reduce cross-country spillovers. On the other side, some have expressed concerns that these arrangements may lead to moral hazard, with countries issuing more debt and defaulting more frequently. Our paper speaks to this debate. Using a two-country model of sovereign default we quantitatively investigate how a set of cross-country agreements impact governments' borrowing decisions, default risk, and welfare.

Our workhorse model is closely related to the one proposed by Arellano et al. (2017). The economy is composed of two countries-Periphery and Outskirt-, and by a continuum of common lenders. The two countries share a common pool of lenders. A key feature of the model is that the lenders are risk averse as in Lizarazo (2013) and Pouzo and Presno (2016). This assumption has a crucial implication for government debt prices: investors' wealth matters. Hence there is the possibility of cross-country contagion. The borrowing and default decisions in one country affect the borrowing terms of the other country through investors' wealth.

We exploit our workhorse model to explore whether a set of cross-country arrangements can reduce contagion and improve welfare. First, we look at the case for bailouts. These are expost policies that are only implemented after defaults are announced. We find that bailouts reduce spillovers and improve welfare as long as they are not anticipated by governments. When, instead, bailouts are anticipated, governments modify their borrowing decision and issue too much debt. As a result, bailouts become more frequent and expensive and welfare declines. All told, we conclude that ex-post policies are counterproductive due to moral hazard.

Second, we look at ex-ante policies that attempt to reduce spillovers before defaults are announced by modifying governments' borrowing incentives. In particular, we look at the scenario in which countries delegate their borrowing decision to a central borrower that 
maximizes global welfare (i.e. the welfare of all the countries in the economy). We find that, in equilibrium, the central borrower issues less debt and defaults less frequently. As a result, global welfare increases. We conclude that ex-ante policies that modify governments' borrowing incentives are preferable to ex-post policies to manage spillover risks.

Finally, we show that Pigouvian taxes on government debt can successfully replicate central borrower's policies in a decentralized framework. Pigouvian taxes should be higher in countries that default more frequently, countercyclical, and increasing with the size of government debt.

Our paper is closely related to Arellano et al. (2017). Similarly to them, we study sovereign contagion in the context of a two-country model in which countries share a common pool of investors and contagion is modeled as wealth effect. However, our paper differs in that we examine the normative implications of such contagion, while Arellano et al. (2017) concentrate on the positive aspects of contagion showing that sovereign contagion explains a large fraction of sovereign spreads' movements during the euro-area debt crises. In particular, we review a number of cross-country agreements and we investigate whether they can mitigate contagion and increase welfare. ${ }^{1}$

A second, closely-related paper, is Bianchi (2016). This paper develops a quantitative model of financial crises and shows that bailouts can improve welfare, but may also generate moral hazard. Our paper is similar in that it also studies the consequences of bailouts on welfare and equilibrium prices and quantities. However, our paper is fundamentally different in that we focus on cross-country bailouts of the sovereign sector, while Bianchi (2016) focuses on bailouts of the domestic financial sector.

The recent work of Gourinchas et al. (2019) is also relevant for us. Gourinchas et al. (2019) estimate the magnitude of cross-country transfers in the context of the euro-area sovereign debt crisis and they find that transfers were large and highly heterogeneous across recipient countries. Additionally, they propose a two-period model in which lenders willingly transfer resources to debtors, to avoid their default. Relatedly, Azzimonti and Quadrini (2018) also develop a two-country model of sovereign defaults with efficient bailouts. In their model, the private sector of each country holds a portfolio of government bonds. As such, a default in one country reduces the wealth of the private sector in the other countries thereby reduc-

\footnotetext{
${ }^{1}$ Park (2013) also proposes a quantitative model of sovereign defaults in which multiple borrowers trade with risk-averse lenders who are subject to capital requirement. Yet, also this paper abstracts from the normative implications of cross-country contagion, which are, instead, the main focus of our paper.
} 
ing production efficiency. Azzimonti and Quadrini (2018) show that, in such environment, creditors may find optimal to bail out debtors to avoid contagion. Our paper also focuses on bailouts and cross-country contagion, however, it differs from Gourinchas et al. (2019) and Azzimonti and Quadrini (2018) along two key dimensions. First, we focus on the "horizontal" contagion between borrowers that share the same investors, while Gourinchas et al. (2019) and Azzimonti and Quadrini (2018) concentrate on the "vertical" contagion from borrowers to lenders. Second, our model is quantitative and aims to quantify the welfare gains of cross-country policies that mitigate sovereign contagion across borrowers. ${ }^{2}$

Recent papers that have studied sovereign risk in the specific context of the European monetary union are also related to ours. These papers concentrate on the interaction between monetary policy and sovereign risk suggesting that the lack of monetary policy independence (Bianchi and Mondragon, 2018) or the coexistence of borrowers and creditors within the union (de Ferra and Romei, 2018) may distort monetary policy and default incentives. Our paper departs from this literature in that we study a contagion channel that works through creditors' balance sheet and exists even in the absence of a common monetary policy. Additionally, we perform a normative analysis and review a set of cross-country policies that are meant to mitigate contagion.

Finally, our paper is related to the theoretical and empirical literatures of contagion through a common investor. On the theoretical front, Kyle (2001) develops a theoretical model showing that investors reduce their exposure to risky investment when their wealth is lower. ${ }^{3}$ Our workhorse model is built on a similar intuition: sovereign defaults reduce investor's wealth generating contagion. On the empirical front, an extensive literature has documented the key role of common investors in explaining the strong market comovements during periods of financial stress. ${ }^{4}$ Broner et al. (2004), for instance, show that portfolio adjustments of international investors explain contagion patterns. In a more recent paper, Converse and Mallucci (2019) analyze micro-level data on investment funds and find that when sovereign risk increases in one country, funds not only pull out from that country, but also from neighboring countries.

The rest of the paper is organized as follows: Section 2 reviews evidence of cross-country

\footnotetext{
${ }^{2}$ de Ferra (2017) shows that private lenders' bailout expectations have been an important driver of gross capital flows between the Euro area and the rest of the world, also contributing to the current account imbalances.

${ }^{3}$ Goldstein and Pauzner (2004) and Yuan (2005) also propose models of financial crises where contagion is modeled as wealth effect.

${ }^{4}$ See Forbes (2012) for an exhaustive overview.
} 
contagion in the sovereign debt market during the euro-area sovereign debt crisis. Section 3 presents the model; Section 4 illustrates how we modify our workhorse model to include policies that aim to mitigate cross-country contagion; Section 5 presents our calibration strategy for the quantitative analysis; Section 6 presents quantitative results obtained simulating our workhorse model; Section 7 presents quantitative result when we allow for cross-country bailouts; finally Section 8 concludes the paper.

\section{Cross-Country Contagion in the Sovereign Debt Mar- ket}

During the euro-area sovereign debt crisis, sovereign stresses quickly spread from Greece and Ireland to other countries in the euro-area periphery. Figure 1 plots sovereign spreads for the euro-area periphery from 2001 to 2019. Spreads display a remarkably similar pattern across countries: they are low in 2001, peak in 2011 and decline in 2014. ${ }^{5}$ Several empirical

Figure 1. Spreads

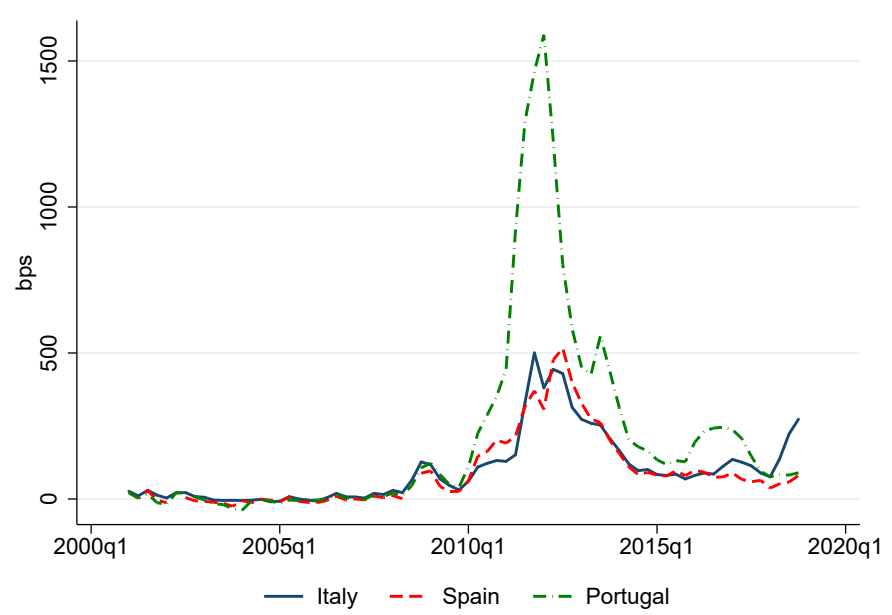

Figure 1 reports 5-year spreads in the euro-area periphery between 2001 and 2018. Spreads are computed relative to the German equivalent. Greece was left out due to scaling issues.

\footnotetext{
${ }^{5}$ Figure 5 in the Appendix, which reports the fraction of countries entering a default in each year from 1900 , also shows that defaults happen in waves.
} 
papers have shown that the cross-country contagion plays an important role in explaining the simultaneous rise in spreads in the euro-area periphery. Beirne and Fratzscher (2013) study cross-country contagion in the euro area estimating a regression model of sovereign credit risk that includes both macroeconomic fundamentals of individual countries and the average credit risk of other European sovereigns. They find that between 2000 and 2011 spreads were $27 \%$ higher in the euro area due cross-country spillovers and Credit Default Swaps (CDS) were 44bp higher due to the risk of cross-country contagion. Constancio (2012) also finds evidence of contagion in a smaller sample that focuses on the euro-area crisis. He analyzes comovements in sovereign bond yields filtering out long-run trends and attributing the remaining correlation to cross-country contagion. He concludes that, in 2011, 38\% of the variance of Italian and Spanish government yields was explained by contagion from Greece, Ireland, and Portugal

A simple inspection of the cross-country correlation between spreads and output also supports the idea that common shocks cannot fully account for spreads' comovement and that cross-country contagion matters. Panel A in Table 1 compares the cross-country correlation of spreads and output shocks in the euro-area periphery from 2001 till the first quarter of 2019. ${ }^{6}$ In pairwise comparisons, we find that the cross-country correlation between spreads is typically higher than the one of output shocks.

Table 1. Cross-country correlations

\begin{tabular}{l|ccc|ccc} 
& \multicolumn{3}{|c|}{ Spreads } & \multicolumn{3}{c}{ Output } \\
& Spain & Greece & Portugal & Spain & Greece & Portugal \\
\hline Italy & 0.92 & 0.63 & 0.85 & 0.76 & 0.19 & 0.70 \\
Spain & 1 & 0.66 & 0.86 & 1 & 0.57 & 0.81 \\
Greece & - & 1 & 0.52 & - & 1 & 0.48
\end{tabular}

Table 1 reports cross-country correlation for spreads and output between the first quarter of 2001 and the last quarter of 2008.

\footnotetext{
${ }^{6}$ Output shocks are obtained removing the linear trend for the log of real GDP
} 


\section{Model}

In this section, we lay down the workhorse two-country model that we use for our normative analysis. The workhorse model is similar to the one proposed by Arellano et al. (2017) with three modifications. First, we do not allow for sovereign debt restructuring. When the government defaults, it defaults on the entire stock of debt and there is no bargaining process with the international investors over the share of government debt that is restructured. Second, we allow for heterogeneity across countries in terms of both their default cost and their endowments process. This allows us to match heterogeneous average levels of debt and the correlation of output across euro-area peripheral economies. Third, we introduce a hierarchy in our decision tree assuming that one of the two countries moves first, while the other moves second after observing the decisions taken by the first county. This assumption is justified by the fact that we calibrate the first mover, which we name Outskirt, to Italy, which is the biggest countries in the euro-area periphery. While we calibrate the second country, which we name Periphery, to the block of the other euro-area peripheral economies (i.e Greece, Spain and Portugal).

\subsection{Environment}

The world economy is composed of two countries, Outskirt $(O)$, Periphery $(P)$ and a common international lender. Both countries are inhabited by a continuum of identical risk-averse households and by a government. The preferences of the representative household in each country are given by:

$$
\mathbb{E}_{0} \sum_{t=0}^{\infty} \beta^{t} u\left(c_{t, i}\right),
$$

where $i \in\{O, P\}$ denotes the country of residence, $\beta$ is the discount factor, and $c_{t, i}$ denotes country $i$ 's consumption of a homogeneous good at time $t$.

In each country households receive a stochastic endowment $y_{i}$ of homogeneous good in every period, as well as a lump-sum transfer from the government of their own country. International lenders, instead, receive a constant endowment of resources $y_{L}$ in every period. Countries may enjoy or lack access to financial markets. The dummy variable $x_{i}$ summarizes exclusion from financial markets of a given country, and it takes the value of one when a country lacks market access, and zero otherwise. The stock of debt of each country is 
denoted by $b_{i}$.

The aggregate state variable in the world economy is a vector $s$ which comprises endowments, debt levels, and market access of Outskirt and Periphery $x_{O}$ and $x_{P}: s=\left\{y_{O}, y_{P}, b_{O}, b_{P}, x_{O}, x_{P}\right\}$

\subsection{International Lenders}

International lenders trade assets with Outskirt and Periphery. Lenders are competitive, and they take aggregate states as given.

Lenders hold assets $b_{L}=\left\{b_{L, i}\right\}_{i \in\{O, P\}}$ against Outskirt and Periphery which pay one unit of the consumption good if debtors do not default. The value of assets held by lenders in each period is

$$
\sum_{i \in\{O, P\}}\left(1-d_{i}\right) b_{L, i}
$$

where $d_{i}$ is the default policy function in $i$, which takes the value of unity in the event of default, and which is taken as given by lenders.

In addition, lenders purchase new assets issued by countries who have access to financial markets and who do not default on their debt. The total amount of resources employed by lenders to purchase assets is given by:

$$
\sum_{i \in\{O, P\}}\left(1-d_{i}\right)\left(1-x_{i}\right) q_{i} b_{L, i}^{\prime}
$$

where $q_{i}$ denotes the price of assets issued by $i$.

The budget constraint of the representative lender is given by:

$$
c_{L}=y_{L}+\sum_{i \in\{O, P\}}\left[\left(1-d_{i}\right)\left(b_{L, i}+\left(1-x_{i}\right) q_{i} b_{P}^{\prime}\right)\right]
$$

As in Arellano et al. (2017) we interpret the exogenous endowment $y_{L}$ as the income from any other assets that investors may hold together with bonds traded with $\mathrm{O}$ and $\mathrm{P} .^{7}$

\footnotetext{
${ }^{7}$ In our model we do allow for the existence of risk-free assets. However, as argued in Kyle (2001), the introduction of risk-free assets does not change the contagion mechanism. When risk-averse investors hold a portfolio of both risky and risk-free assets and one of the risky asset underperforms, investors will rebalance away from all risky assets and toward the risk-free asset.
} 
The problem faced by lenders is to purchase the optimal amount of bonds issued by Outskirt and Periphery to maximize their expected lifetime welfare. Formally, their value function $V_{L}$ is defined as follows:

$$
\begin{gathered}
V_{L}\left(s, b_{L}\right)=\max _{c_{L}, b_{L}^{\prime}} u\left(c_{L}\right)+\beta_{L} \mathbb{E}\left[V_{L}\left(s^{\prime}, b_{L}^{\prime}\right)\right], \\
\text { s.t. } c_{L}=y_{L}+\sum_{i \in\{O, P\}}\left[\left(1-d_{i}\right)\left(b_{L, i}+\left(1-x_{i}\right) q_{i} b_{L}^{\prime}\right)\right] .
\end{gathered}
$$

The first-order conditions of investors' maximization problem yield the asset pricing equations for government bonds:

$$
q_{i}\left(s^{\prime}, b_{L}^{\prime}\right)=\beta_{L} \frac{E\left[u_{c}\left(c_{L}^{\prime}\right)\left(1-d_{i}\right)\right]}{u_{c}\left(c_{L}\right)} .
$$

Where $U_{c}$ denotes the derivative of the utility function with respect to consumption. The possibility of cross-country arises because investors are risk averse. Government borrowing and default decisions in one country affect investors' wealth, thereby affecting borrowing terms in the other country. Hence, in this framework, contagion is possible: a default in one country may worsen borrowing terms in the other country.

Equation (7) can be further decomposed into a credit-risk component and the risk premium as follows:

$$
q_{i}\left(s^{\prime}, b_{L}^{\prime}\right)=\beta_{L} \frac{E\left[u_{c}\left(c_{L}^{\prime}\right)\right]}{u_{c}\left(c_{L}\right)}\left(1-P\left(d_{i}\right)\right)+\frac{\operatorname{Cov}\left(u_{c}\left(c_{L}^{\prime}\right),\left(1-d_{i}\right)\right)}{u_{c}\left(c_{L}\right)} .
$$

The first term is the credit-risk component and it captures the fact that bond prices decline when default risk increases. As investors are risk averse, the stochastic discount factor $\beta_{L} E\left[u_{c}\left(c_{L}^{\prime}\right)\right] / u_{c}\left(c_{L}\right)$ also appears in the asset pricing equation introducing the possibility of contagion. The second term is the risk premium. As explained in Lizarazo (2013), this terms captures the fact that the correlation between investors' consumption and default risk matters for the price of government bonds when the marginal investor is risk averse. Bond prices, indeed, reflect the fact that investors are less willing to hold assets whose payoff is low in states of the world where consumption is also low. 


\subsection{Outskirt and Periphery}

Governments of Outskirt and Periphery trade bonds with foreign investors to maximize households' welfare. Outskirt and Periphery are symmetrical except for the fact that Outskirt is a bigger economy that moves first, while Periphery is a smaller economy that moves second. For the sake of brevity, we only report the decisions problem for the government of Outskirt in the main body of the paper. The maximization problem for the government of Periphery is reported in Appendix 9.2. Of note, the two problems only differ in that the government of Outskirt needs to formulate forecasts over the borrowing and default decisions of Periphery, while Periphery, being the follower, directly observes Outskirt's policies.

\subsection{Outskirt's Government Problem when Periphery has Access to Financial Markets}

To ease the expositions we first lay out the maximization problem of Outskirt when Periphery has access to financial markets. We then move to the case in which Periphery has no market access.

Outskirt's optimal default decision $d_{O}$, conditional on both countries having access to the financial market, solves

$$
W=\max _{d_{O}}\left\{\left(1-d_{O}\right) W^{n d}+d_{O} W^{d}\right\}
$$

Where $W^{n d}$ and $W^{d}$ are Outskirt's value functions in the non-default and in the default scenarios and where $d_{O}$ is an indicator taking the value of one in case Outskirt defaults.

The value function $W^{n d}$ is the solution to the following maximization problem:

$$
\begin{array}{r}
W^{n d}\left(y_{O}, y_{P}, b_{O}, b_{P}\right)=\max _{c_{O}, b_{O}^{\prime}} u\left(c_{O}\right)+\beta \mathbb{E}\left[\left(1-\hat{d}_{P}^{\prime}\right) W\left(y_{O}^{\prime}, y_{P}^{\prime}, \hat{b}_{O}^{\prime}, \hat{b_{P}^{\prime}}\right)\right. \\
\left.+\hat{d}_{P}^{\prime} W_{\text {only } O}\left(y_{O}^{\prime}, y_{P}^{\prime}, b_{O}^{\prime}\right)\right] \\
\text { s.t. } c_{O}=A_{O} y_{O}+q_{O} b_{O}^{\prime}-b_{O},
\end{array}
$$




$$
\begin{gathered}
q_{O}=\beta_{L} \frac{E\left[u_{c_{L}^{\prime}}\left(c_{L}^{\prime}\right)\left(1-d_{P}\right)\right]}{u_{c_{L}}\left(c_{L}\right)}, \\
{\hat{b_{P}}}^{\prime}=H\left(y_{O}, y_{P}, b_{O}, b_{P}\right), \\
\hat{d}_{P}=D\left(y_{O}, y_{P}, b_{O}, b_{P}\right) .
\end{gathered}
$$

Equation (11) is Outskirt's resource constraint and states that consumption equals the endowment plus net imports from abroad. Parameter $A_{O}$ is a scalar that is introduced to keep track of the fact that Outskirt and Periphery have different size. ${ }^{8}$ Equation (12) is the asset pricing equation that in consistent with the maximization problem of international investors. Constraints (13) and (14) are Outskirt's forecasting rules for the borrowing and default decisions of Periphery. They are included in the set of constraints as Outskirt moves first and therefore has to consider how it actions influence Periphery's policies. ${ }^{9}$

If the government chooses to default or it lacks access to financial markets, the economy suffers an output cost of exclusion. In the setting, the country's endowment is reduced to $\varphi_{O} A_{O} y_{O}$, where $\varphi_{O} \leq 1$. Outskirt can re-gain access to financial markets with exogenous probability $\lambda_{O}$.

Conditional on Periphery having access to financial markets, Outskirt's value function in case of default is:

$$
\begin{gathered}
W^{d}\left(y_{O}, y_{P}, b_{P}\right)=u\left(c_{O}\right)+\beta \mathbb{E}\left[\left(1-\lambda_{O}\right) W^{d}\left(y_{O}^{\prime}, y_{P}^{\prime}, b_{P}^{\prime}\right)+\lambda_{O} W\left(y_{O}^{\prime}, y_{P}^{\prime}, 0, b_{P}^{\prime}\right)\right] \\
\text { s.t. } c_{O}=\varphi_{O} A_{O} y_{O}, \\
{\hat{b_{P}}}^{\prime}=H\left(y_{O}, y_{P}, b_{P}\right), \\
\hat{d}_{P}=D\left(y_{O}, y_{P}, b_{P}\right) .
\end{gathered}
$$

\footnotetext{
${ }^{8}$ In the calibration exercise we set $A_{O}=1$ and $A_{P}=0.92$ to replicate the fact that the cumulated GDP of Greece, Spain and Portugal is about $92 \%$ of the Italian GDP

${ }^{9}$ In the maximization problem of the Periphery forecasting rules (13) and (14) are replaced by the Outskirt's actual borrowing and default decision.
} 
Once again, 3.0 equation (16) is the resource constraint in Outskirt, while equations (17) and (18) represent, respectively, the forecasting rules for Periphery's borrowing and default decisions.

\section{Outskirt's Government Problem when Periphery is in Autarky}

We now turn to the case in which Periphery does not have access to financial markets. The optimal default decision $d_{\text {onlyo }}$ of Outskirt, conditional on Periphery being in autarky solves:

$$
W_{\text {onlyO }}=\max _{d_{\text {onlyO }}}\left\{\left(1-d_{\text {onlyO }}\right) W_{\text {onlyO }}^{\text {nd }}+d_{\text {onlyO }} W_{\text {onlyO }}^{d}\right\}
$$

$W_{o n l y O}^{n d}$ and $W_{\text {onlyO }}^{d}$ are Outskirt's value functions in the non-default and in the default scenarios when Periphery is in autarky.

Outskirt's value function $W_{\text {only } O}^{n d}$ solves the following maximization problem:

$$
\begin{gathered}
W_{\text {only } O}^{n d}\left(y_{O}, y_{P}, b_{O}\right)=\max _{c_{O}, b_{O}^{\prime}} u\left(c_{O}\right)+\beta \mathbb{E}\left[\left(1-\lambda_{P}\right) W_{\text {only } O}\left(y_{O}^{\prime}, y_{P}^{\prime}, b_{O}^{\prime}\right)+\right. \\
\left.\lambda_{P} W\left(y_{O}^{\prime}, y_{P}^{\prime}, b_{O}^{\prime}, 0\right)\right] \\
\text { s.t. } c_{O}=A_{O} y_{O}+q_{\mathrm{only} O} b_{O}^{\prime}-b_{O}, \\
q_{O}=\beta_{L} \frac{E\left[u_{c}\left(c_{L}^{\prime}\right)\left(1-d_{\mathrm{only} O}\right)\right]}{u_{c}\left(c_{L}\right)} .
\end{gathered}
$$

Of note, the exogenous probability $\lambda_{P}$ that Periphery is readmitted to financial markets shows up in the continuation value of Outskirt's objective function (20) as Periphery access to financial market also affects Outskirt's welfare through borrowing rates. Equations (21) and (22) are Outskirt's budget constraint and the asset pricing equations for government bonds, respectively.

Conditional on Periphery being in autarky, Outskirt's value function in case of default is:

$$
\begin{aligned}
W_{\text {only } O}^{d}\left(y_{O}, y_{P}\right)= & u\left(c_{O}\right)+\beta \mathbb{E}\left\{\lambda_{P}\left[\left(1-\lambda_{O}\right) W^{d}\left(y_{O}^{\prime}, y_{P}^{\prime}, 0\right)+\lambda_{O} W\left(y_{O}^{\prime}, y_{P}^{\prime}, 0,0\right)\right]\right. \\
& \left.+\left(1-\lambda_{P}\right)\left[\left(1-\lambda_{O}\right) W_{\text {only } O}^{d}\left(y_{O}^{\prime}, y_{P}^{\prime}\right)+\lambda_{O} W_{\text {only } O}\left(y_{O}^{\prime}, y_{P}^{\prime}, 0\right)\right]\right\}
\end{aligned}
$$




\subsection{Recursive Markov Perfect Equilibrium}

We define the recursive Markov perfect equilibrium in three steps. First, we define the equilibrium for the subgame of Outskirt. Second, we define the equilibrium for the subgame of Periphery. Finally, we formally define the recursive Markov perfect equilibrium.

Equilibrium for Outskirt's Subgame: The equilibrium for the subgame played by Outskirt is a set of policies $\left\{d_{O}^{*}, b_{O}^{\prime *}\right\}$ and consumption plans $\left\{c_{O}\right\}$, such that the government of Outskirt solves the maximization problem of the representative households, given Outskirt and Periphery market access $\left\{x_{O}, x_{P}\right\}$, a forecasting rule for the borrowing and default decisions of the Periphery $\left\{\hat{b}_{P}^{\prime}, \hat{d}_{P}\right\}$, and the pricing schedule $q_{O}\left(s^{\prime}, b_{O}^{\prime}, \hat{b}_{P}^{\prime}\right)$.

Equilibrium for Periphery's Subgame: The equilibrium for the subgame played by Periphery is a set of policies $\left\{d_{P}^{*}, b_{P}^{*}\right\}$ and consumption plans $\left\{c_{P}^{*}\right\}$, such that the government of Periphery solves the maximization problem of the representative households, given Outskirt and Periphery market access $\left\{x_{O}, x_{P}\right\}$, Outskirt borrowing decision $\left\{b_{O}^{* *}\right\}$, and the pricing schedule $q_{P}\left(s^{\prime}, b_{O}^{*}, b_{P}^{\prime}\right)$.

Recursive Markov Equilibrium: The recursive Markov equilibrium is a set of polices $\left\{d_{O}^{*}, d_{P}^{*}, b_{O}^{*}, b_{P}^{* *}\right\}$, consumption plans $\left\{c_{O}^{*}, c_{P}^{*}\right\}$, and prices $\left\{q_{O}^{*}, q_{P}^{*}\right\}$, such that:

- $\left\{d_{O}^{*}, b_{O}^{*}\right\}$ and $\left\{c_{O}^{*}\right\}$ solve the subgame of Outskirt

- $\left\{d_{P}^{*}, b_{P}^{*}\right\}$ and $\left\{c_{P}^{*}\right\}$ solve the subgame of Periphery.

- Prices $\left\{q_{O}^{*}, q_{P}^{*}\right\}$ are consistent with the maximization problem of investors

- Outskirt forecasting rule are consistent with Periphery policies: $\hat{b}_{P}^{\prime}=b_{P}^{*}$ and $\hat{d}_{P}=$ $\operatorname{de} f_{P}^{*}$ 


\section{Normative Analysis}

In this section we review a number of ex-post and ex-ante policies that can reduce contagion and improve welfare. Ex-post policies, such as bailouts, are implemented only after defaults are announced. Ex-ante policies, such as the imposition of borrowing rules, are implemented in normal times and are meant to reduce the incidence and the severity of crises before they occur.

In light of the euro-area experience we focus on four policies. First, we look at bailouts when agents do not anticipate their existence prior to the occurrence of a crisis (unanticipated bailouts). Second we look at a setting in which agents are aware that bailouts may be implements in the even of a crisis (anticipated bailouts). Third, we look at the institution of a centralized borrower that takes the borrowing decision on behalf of individual governments, maximizing global welfare. Finally, we look at a Pigouvian taxes on debt that reduce governments' borrowing incentives.

\subsection{Bailouts}

When either of the two countries defaults, investors' wealth declines. This in turn affect the borrowing terms of the other country through the stochastic discount factor of the lender. Due to the existence of spillovers, countries may find it optimal to implement bailouts in the form of cross-country transfers to reduce the incidence of defaults and limit welfare losses. In this section we look at both unanticipated and anticipated bailouts.

\section{Unanticipated Bailouts}

Unanticipated bailouts are cross-country transfers that take place after one country has announced a default and before the default has actually taken place. As unanticipated bailouts are unexpected, they only affect governments' default decisions, but they do not affect governments' borrowing policy.

The sequence of the events for unanticipated bailouts is the following:

- Endowment shocks are realized. 
- Governments make their optimal borrowing choices and default plans.

- Before strategies are implemented, governments learn that they can implement crosscountry transfers to avoid defaults. The possibility of bailouts comes as a surprise and governments cannot modify their previously chosen borrowing policies.

- The government that intends to default announces the minimal transfer $T_{\text {min }}$ needed to avoid a default.

- The government that does not intend to default evaluates bailout requests and decides whether to provide the support.

- Default, borrowing, and bailout plans are implemented

Bailouts are welfare improving by construction, as they are only implemented when they are beneficial to both countries. Suppose that Periphery decides to default and let $T_{\min }^{P}$ be the transfer from Outskirt to Periphery that makes Periphery indifferent between defaulting or not:

$$
u\left(A_{P} y_{P}-b_{P}+q_{P} b_{P}^{\prime}+T_{m i n}^{P}\right)+\beta \mathbb{E}\left[V\left(y_{O}^{\prime}, y_{P}^{\prime}, b_{O}^{\prime}, b_{P}^{\prime}\right)\right]=V^{d}\left(y_{O}, y_{P}, b_{O}\right) .
$$

Also let $T_{\max }^{P}$ be the transfer from Outskirt to Periphery that makes Outskirt indifferent between bailing out Periphery or letting it default:

$$
u\left(A_{O} y_{O}-b_{O}+q_{O} b_{O}^{\prime}-T_{\max }^{P}\right)+\beta \mathbb{E}\left[W\left(y_{O}^{\prime}, y_{P}^{\prime}, b_{O}^{\prime}, b_{P}^{\prime}\right)\right]=W_{\text {only } O}\left(y_{O}, y_{P}, b_{O}\right) .
$$

Bailouts can only be implemented if

$$
T_{\max }^{P} \geq T_{\min }^{P}>0
$$

Condition (27) can be decomposed in three sub-conditions. Sub-condition $T_{\min }^{P}>0$ ensures that Periphery wants to default. Sub-condition $T_{\max }^{O}>0$ ensures that Outskirt is better off if Periphery does not default. Finally, sub-condition $T_{\max }^{P} \geq T_{\min }^{P}$ ensures that the maximal transfer that Outskirt is willing to supply is larger than the minimal transfer needed by Periphery. When all the three sub-conditions are met, any transfer $T^{P} \in\left(T_{\min }^{P}, T_{\max }^{P}\right)$ avoids a default in the Periphery and increases the welfare of both Outskirt and Periphery. ${ }^{10} \mathrm{We}$ define Periphery's "transfer area" the area of the state space where condition (27) holds. ${ }^{11}$

\footnotetext{
${ }^{10}$ Bailouts only happen if both countries have access to financial markets. It is never optimal for countries in autarky to bail out countries that have access to financial markets because they do not benefit from the better borrowing terms.

${ }^{11}$ The definition of Outskirt's transfer area is symmetric.
} 


\section{Anticipated Bailouts}

Rational agents should anticipate the existence of bailouts and modify their borrowing and default decisions accordingly. In this section we lay out the inter-temporal problem of Outskirt and Periphery's governments when bailouts are anticipated.

Let $\mathbb{1}_{P}^{T}$ be an indicator function that is equal to one when Outskirt bails out Periphery. Also, let $\hat{\mathbb{1}}_{O}^{T}$ be Outskirt's forecast rule for Periphery's bailout policy. Outskirt's optimal bailout and default policies $\mathbb{1}_{P}^{T}, d_{O}$, conditional on both countries having access to financial markets, solve:

$$
W=\max _{d_{O}, \mathbb{1}_{P}^{T}}\left\{\left(1-d_{O}\right)\left[\left(1-\mathbb{1}_{P}^{T}\right) W^{n d}+\mathbb{1}_{P}^{T} W^{T_{P}}\right]+d_{O}\left(\left(1-\hat{\mathbb{1}}_{O}^{T}\right) W^{d}+\hat{\mathbb{1}}_{O}^{T} W^{T_{O}}\right)\right\}
$$

Where value functions $W^{d}$ and $W^{n d}$, defined in Section 3.3, are Outskirt's value function when bailouts are not implemented and value functions $W^{T_{P}}$ and $W^{T_{O}}$ are Outskirt's value function when bailouts are implemented.

Outskirt's value function $W^{T_{P}}$, when Outskirt supplies a transfer to Periphery, is the solution to the following maximization problem:

$$
\begin{aligned}
& W^{T_{P}}\left(y_{O}, y_{P}, b_{O}, b_{P}\right)=\max _{c_{O}, b_{O}^{\prime}} u\left(c_{O}\right)+\beta \mathbb{E}\left[\left(1-\hat{d}_{P}^{\prime}\right) W\left(y_{O}^{\prime}, y_{P}^{\prime}, b_{O}^{\prime}, \hat{b}_{P}^{\prime}\right)\right. \\
& +\hat{d}_{P}^{\prime}\left(1-\mathbb{1}_{P}^{T}\right) W_{\text {only } O}\left(y_{O}^{\prime}, y_{P}^{\prime}, b_{O}^{\prime}\right) \\
& \left.+\hat{d}_{P}^{\prime} \mathbb{1}_{P}^{T} W\left(y_{O}^{\prime}, y_{P}^{\prime}, b_{O}^{\prime}, \hat{b}_{P}^{\prime}\right)\right] \\
& \text { s.t. } c_{O}=A_{O} y_{O}+q_{O} b_{O}^{\prime}-b_{O}-T_{P} \text {, } \\
& q_{O}=\beta_{L} \frac{E\left[u_{c_{L}^{\prime}}\left(c_{L}^{\prime}\right)\left(1-d_{P}\right)\right]}{u_{c_{L}}\left(c_{L}\right)}, \\
& {\hat{b_{P}}}^{\prime}=H\left(y_{O}, y_{P}, b_{O}, b_{P}\right) \text {. } \\
& \hat{d}_{P}=D\left(y_{O}, y_{P}, b_{O}, b_{P}\right)
\end{aligned}
$$




$$
T_{P}=T_{\min }^{P}+\psi
$$

Where $T_{\text {min }}^{P}$ is the minimal transfer that Outskirt needs to receive to remain in the market and equations (31), (32), and (33) are respectively the asset pricing equation for Outskirt's bonds, and the forecasting rules for the Periphery's borrowing and default policies.

Finally, Outskirt's value function $W^{T_{O}}$, when Outskirt receives a transfer from Periphery, is solution to the following maximization problem:

$$
\begin{aligned}
& W^{T_{O}}\left(y_{O}, y_{P}, b_{O}, b_{P}\right)=\max _{c_{O}, b_{O}^{\prime}} u\left(c_{O}\right)+\beta \mathbb{E}\left[\left(1-\hat{d}_{P}^{\prime}\right) W\left(y_{O}^{\prime}, y_{P}^{\prime}, b_{O}^{\prime}, \hat{b}_{P}^{\prime}\right)\right. \\
& +\hat{d}_{P}^{\prime}\left(1-\mathbb{1}_{P}^{T}\right) W_{\text {onlyO }}\left(y_{O}^{\prime}, y_{P}^{\prime}, b_{O}^{\prime}\right) \\
& \left.+\hat{d}_{P}^{\prime} \mathbb{1}_{P}^{T} W\left(y_{O}^{\prime}, y_{P}^{\prime}, b_{O}^{\prime}, \hat{b}_{P}^{\prime}\right)\right] \\
& \text { s.t. } c_{O}=A_{O} y_{O}+q_{O} b_{O}^{\prime}-b_{O}+T_{O} \text {, } \\
& q_{O}=\beta_{L} \frac{E\left[u_{c}\left(c_{L}^{\prime}\right)\left(1-d_{P}\right)\right]}{u_{c}\left(c_{L}\right)} \\
& \hat{b}_{P}^{\prime}=H\left(y_{O}, y_{P}, b_{O}, b_{P}\right) . \\
& \hat{d}_{P}=D\left(y_{O}, y_{P}, b_{O}, b_{P}\right) \\
& \hat{d}_{P}=D\left(y_{O}, y_{P}, b_{O}, b_{P}\right) \\
& T_{O}=T_{m i n}^{O}+\psi
\end{aligned}
$$

Where $T_{\text {min }}^{O}$ is the minimal transfer that Outskirt needs to receive to remain in the market.

With the introduction of anticipated bailouts, value functions account for the existence of cross-country transfers. As such, not only do bailouts affect equilibrium outcomes when they are implemented. They also affect government policies whenever there is the expectation that they may be implemented in the future. In particular, bailout expectations alter 
governments' borrowing incentives.

The maximization problems that define Periphery's value function $V^{T_{P}}$ and $V^{T_{P}}$ are symmetric and are not reported for brevity. ${ }^{12}$

\subsection{Central Borrower}

The third policy we consider is the creation of a super-national entity-the central borrowerthat takes the borrowing decision on behalf of the individual countries, while individual governments retain full control on the default decision. ${ }^{13}$ This policy is meant to capture the existance of supernational fiscal rules that limit governments' ability to borrow. Here, we consider the case where such rules are very stringent and the central borrower fully controls borrowing decisions.

We report below the maximization problem of the central borrower when both Outskirt and Periphery have access to financial markets. Section 9.3 of the Appendix reports central borrower's maximization problems in all the other cases. The central borrower maximizes the joint utility of the two governments. In so doing, it fully internalize spillovers from one country to the other.

Value function $G$ is the solution to the maximization problem of the central borrower when both Outskirt and Periphery have access to financial markets:

$$
\begin{array}{r}
G\left(y_{O}, y_{P}, b_{O}, b_{P}\right)=\max _{c_{O}, b_{O}^{\prime}, c_{P}, b_{P}^{\prime}} u\left(c_{O}\right)+u\left(c_{P}\right)+\beta \mathbb{E}\left[\left(1-d_{O}\right)\left(1-d_{P}\right) G\left(y_{O}^{\prime}, y_{P}^{\prime}, b_{O}^{\prime}, b_{P}^{\prime}\right)\right. \\
+d_{O} d_{P} G^{d}\left(y_{O}^{\prime}, y_{P}^{\prime}\right)+d_{O}\left(1-d_{P}\right) G_{\text {only } P}\left(y_{O}^{\prime}, y_{P}^{\prime}, b_{P}^{\prime}\right) \\
\left.+\left(1-d_{O}\right) d_{P} G_{\text {only } O}\left(y_{O}^{\prime}, y_{P}^{\prime}, b_{O}^{\prime}\right)\right]
\end{array}
$$

\footnotetext{
${ }^{12}$ In Periphery's maximization problems forecast rules are replaced by the actual policy functions as Periphery observes Outskirt policies before making its own choices.

${ }^{13}$ The assumption that governments retain control over the default policy derives from the standard assumption that government cannot commit to repay their debt. Additionally, we maintain the assumptions that resources cannot be redistributed across countries, and that countries cannot lend to each other.
} 


$$
\begin{aligned}
& q_{O}=\beta_{L} \frac{E\left[u_{c}\left(c_{L}^{\prime}\right)\left(1-d_{O}\right)\right]}{u_{c}\left(c_{L}\right)}, \\
& q_{P}=\beta_{L} \frac{E\left[u_{c}\left(c_{L}^{\prime}\right)\left(1-d_{P}\right)\right]}{u_{c}\left(c_{L}\right)} .
\end{aligned}
$$

Where $d_{O}$ and $d_{P}$ are the default policy functions in Outskirt and Periphery that are taken by individual governments comparing their value function in the default scenario and in the non-default scenario and given the borrowing choices imposed by the central borrwer.

\subsection{Pigouvian Taxes}

The institution of a central borrower may prove complicated as countries need to give up their sovereignty. However, the same equilibrium can be achieved in a decentralized setting with Pigouvian taxes on government debt. Let $\tau$ be a Pigouvian tax that is levied on government debt by a supranational entity and is rebated to governments in a lump-sum fashion. Outskirt budget constraint becomes:

$$
c_{O}=A_{O} y_{O}+q_{O}\left(1-\tau_{O}\right) b_{O}^{\prime}-b_{O}+T
$$

Assuming, for illustrative purposes, that Outskirt's price function and value function are differentiable, we can replace equation (11) with (47) in problem (10) and derive the following first order condition for government bonds:

$$
u_{c}\left(c_{O}\right) q_{O}\left(1-\tau_{O}\right)+u_{c}\left(c_{O}\right) \frac{\partial q_{O}}{\partial b_{O}^{\prime}} b_{O}^{\prime}\left(1-\tau_{O}\right)=\beta E\left[u_{c}\left(c_{O}^{\prime}\right)\right] \cdot{ }^{14}
$$

From the maximization problem (42), we can derive the corresponding first order condition when the borrowing decision is taken by the central borrower:

$$
\left(1-d_{O}\right)\left(u_{c}\left(c_{o}\right) q_{O}+u_{c}\left(c_{O}\right) \frac{\partial q_{O}}{\partial b_{O}^{\prime}} b_{O}^{\prime}\right)+\left(1-d_{O}\right)\left(u_{c}\left(c_{P}\right) \frac{\partial q_{P}}{\partial b_{O}^{\prime}} b_{P}^{\prime}\right)=\beta E\left[u_{c}\left(c_{O}^{\prime}\right)\right]
$$

\footnotetext{
${ }^{14}$ The value functions and the price function for government debt are generally not differentiable due to the nonlinearity introduced by sovereign defaults.
} 
The tax rate that equates Periphery's borrowing policies to those of the central borrower, when neither Outskirt nor Periphery defaults, is:

$$
\tau_{O}=-\frac{u_{c}\left(c_{P}\right)}{u_{c}\left(c_{O}\right)} \frac{\frac{\partial q_{P}}{\partial b_{O}^{\prime}} b_{P}^{\prime}}{\frac{\partial q_{O}}{\partial b_{O}^{\prime}} b_{O}^{\prime}+q_{O}} .
$$

From (50) it is easy to see that the Pigouvian rate is increasing in the size of Outskirt's debt; is decreasing with the price of Outskirt's debt; and-as long as $\left(\frac{\partial q_{O}}{\partial b_{O}^{\prime}} b_{O}^{\prime}+q_{O}\right)>0$-is increasing in the size of Periphery's debt. The properties of the Pigouvian tax rate are consistent with the tax rate being higher when the risk of contagion is stronger.

\section{Calibration and Functional Forms}

We calibrate the model so that Outskirt replicates the annual evolution of Italy and Periphery replicates the rest of the euro-area periphery: Greece, Portugal, and Spain. Given the strong economic connection between euro-area peripheral economies we assume that the exogenous endowment process $y_{O}$ and $y_{P}$ follow a multivariate $\operatorname{AR}(1)$ process:

$$
\left[\begin{array}{c}
z_{O, t} \\
z_{P, t}
\end{array}\right]=\left[\begin{array}{cc}
\rho_{O O} & \rho_{O P} \\
\rho_{P O} & \rho_{P P}
\end{array}\right]\left[\begin{array}{c}
z_{O, t-1} \\
z_{P, t-1}
\end{array}\right]+\left[\begin{array}{c}
\varepsilon_{O, t} \\
\varepsilon_{P, t}
\end{array}\right] .
$$

Shocks $\varepsilon_{O, t}$ and $\varepsilon_{P, t}$ are extracted from a multivariate normal distribution with zero mean and a variance-covariance matrix defined as follows:

$$
\Omega=\left[\begin{array}{cc}
\sigma_{O O}^{2} & \sigma_{O P} \\
\sigma_{O P} & \sigma_{P P}^{2}
\end{array}\right]
$$

Parameter $\sigma_{O P}$ captures the correlation between shocks in Outskirt and Periphery.

The utility functions of Outskirt, Periphery, and the international investors take the standard CRRA form:

$$
U\left(C_{i}\right)=\frac{\left(c_{i}\right)^{1-\sigma}}{1-\sigma},
$$

where parameter $\sigma$ determines the degree of risk aversion.

Following Chatterjee and Eyigungor (2012) we assume that the output cost of default is 
quadratic in the output:

$$
\varphi_{i} \equiv 1-\max \left\{0 ; \varphi_{i, 1}+\varphi_{i, 2} A_{i} y_{i}\right\}
$$

Table 2 reports parameters for the calibration. Parameters above the line are calibrated independently either targeting moments from the data or choosing values that are standard in the literature. Parameters below the line are jointly determined using the method of moments targeting the average debt-to-GDP ratios in Italy and in the rest of the euro-area periphery and the average spreads. Investors' exogenous income $y_{L}$ and the parameter $A_{O}$ for

Table 2. Calibration

\begin{tabular}{llcl}
\hline \hline Calibrated Parameter & & Value & Source/Target Statistics \\
\hline \hline Output Scalar - $P$ & $A_{P}$ & 0.91 & Relative Output: GR\&PT\&SP/IT \\
Lenders' discount factor & $\beta_{I}$ & 0.995 & 5-year German Bund \\
Borrowers' discount factor & $\beta$ & 0.845 & Standard \\
Re-entry probability - $O$ & $\lambda_{O}$ & 0.19 & Euro-area debt crisis \\
Re-entry probability - $P$ & $\lambda_{P}$ & 0.19 & Euro-area debt crisis \\
Autocorrel. TFP shocks & $\rho_{O O}$ & 0.91 & \\
Autocorrel. TFP shocks & $\rho_{O P}$ & -0.13 & Output process \\
Autocorrel. TFP shocks & $\rho_{P O}$ & -0.03 & \\
Autocorrel. TFP shocks & $\rho_{P P}$ & 0.88 & in Italy, Greece, \\
Std. Dev $O$ shock & $\sigma_{O O}$ & 0.019 & \\
Std. Dev $P$ shock & $\sigma_{P P}$ & 0.039 & Portugal, and Spain \\
Covariance $O$ P shocks & $\sigma_{O P}$ & 0.014 & \\
Risk Aversion & $\sigma$ & 2 & Standard \\
\hline Cost Parameter - $O$ & $\varphi_{1}^{O}$ & -0.151 & Debt/GDP IT : 0.07 \\
Cost Parameter - $P$ & $\varphi_{1}^{P}$ & -0.146 & Debt/GDP GR\&PT\&SP*: 0.06 \\
Cost Parameter - $O$ & $\varphi_{2}^{O}$ & 0.175 & Mean Spread IT: 99 bp \\
Cost Parameter - $P$ & $\varphi_{2}^{P}$ & 0.194 & Mean Spread GR\&PT\&SP 204 bps \\
\hline \hline
\end{tabular}

Table 2 reports parameter values that are used for the calibration and the associated target statistics. Parameters above the line are calibrated independently either targeting moments from the data or choosing values that are standard in the literature. Parameters below the line are jointly determined using the method of moments targeting the average debt-to-GDP ratios in Italy and in the rest of the euro-area periphery and the average spreads.

*Debt $b$ is defined as foreign-held debt with a residual maturity of less than one year.

the output of Outskirt are normalized to $1 .{ }^{15}$ The corresponding parameter $A_{P}$ for Periphery

\footnotetext{
${ }^{15}$ In section 9.5 we perform a sensitivity analysis showing how our results would change when we set $y_{L}$ different from 1. Results in section 6.2 show that contagion patterns with $y_{L}=1$ are consistent with empirics.
} 
is, instead, set equal to 0.91 reflecting the fact that the joint output of Greece, Portugal and Spain is roughly $91 \%$ of the Italian GDP. Output

Lender's discount factor $\beta_{L}$ is set equal to 0.995 to replicate the average annual real return of 5-year German bonds between 2001 and 2018. The quarterly government's discount factor $\beta$ is set equal to 0.845 which correspond to the standar annual discount rate of 0.96 . Parameters $\lambda_{O}$ and $\lambda_{P}$ determine countries' probability to regain access to financial markets. Greece lost market access from the second quarter of 2010 till the third quarter of 2018. Portugal was excluded from financial markets from the first quarter of 2011 till the second quarter of 2013. On average, the exclusion time, was a little longer than five years giving a re-entry probability of 0.19 that we use for both Outskirt and Periphery. The risk-aversion parameter $\sigma$ for the utility function is set equal to 2 as it is standard in the literature.

Parameters that define the output processes are calibrated running a VAR with annual GDP data from 1970 to 2011 for the two country blocks. ${ }^{16}$ The positive sign of the covariance term $\sigma_{O P}$ suggests that countries in the euro-area periphery are subject to common endowment shocks. Estimates of autocorrelation parameters show, instead, that endowment processes are strongly autocorrelated within country blocks.

Cost parameters are calibrated using the simulated method of moments targeting the debtto-GDP ratios and the mean spreads for the Italy and the Greece-Portugal-Spain block. ${ }^{17}$ As the model only allows for external debt with one-year maturity, we target the debt-to-GDP ratio for government debt held by external investor with maturity of less than one year. This is $7 \%$ in the Italy and $6 \%$ in the rest of the euro-area periphery.

\section{Quantitative Analysis}

\subsection{Sovereign Contagion}

When either country defaults, investors suffer a wealth loss. This in turn affects the borrowing terms of the other county through the stochastic discount factor of the lender. Panel A in Figure 2 compares the price functions for Outskirts's debt when Periphery enjoys market

\footnotetext{
${ }^{16} \mathrm{GDP}$ series are collected from the World Bank database, and they are logged, demeaned and detrended. ${ }^{17}$ Spreads for Greece are not available between 2012 and 2016 as the country had no access to financial market.
} 
access and when it does not. When Periphery is in autarky, Outskirt's borrowing terms worsen. Cross-country spillovers may even lead to "sovereign default contagion". That is,

Figure 2. Contagion
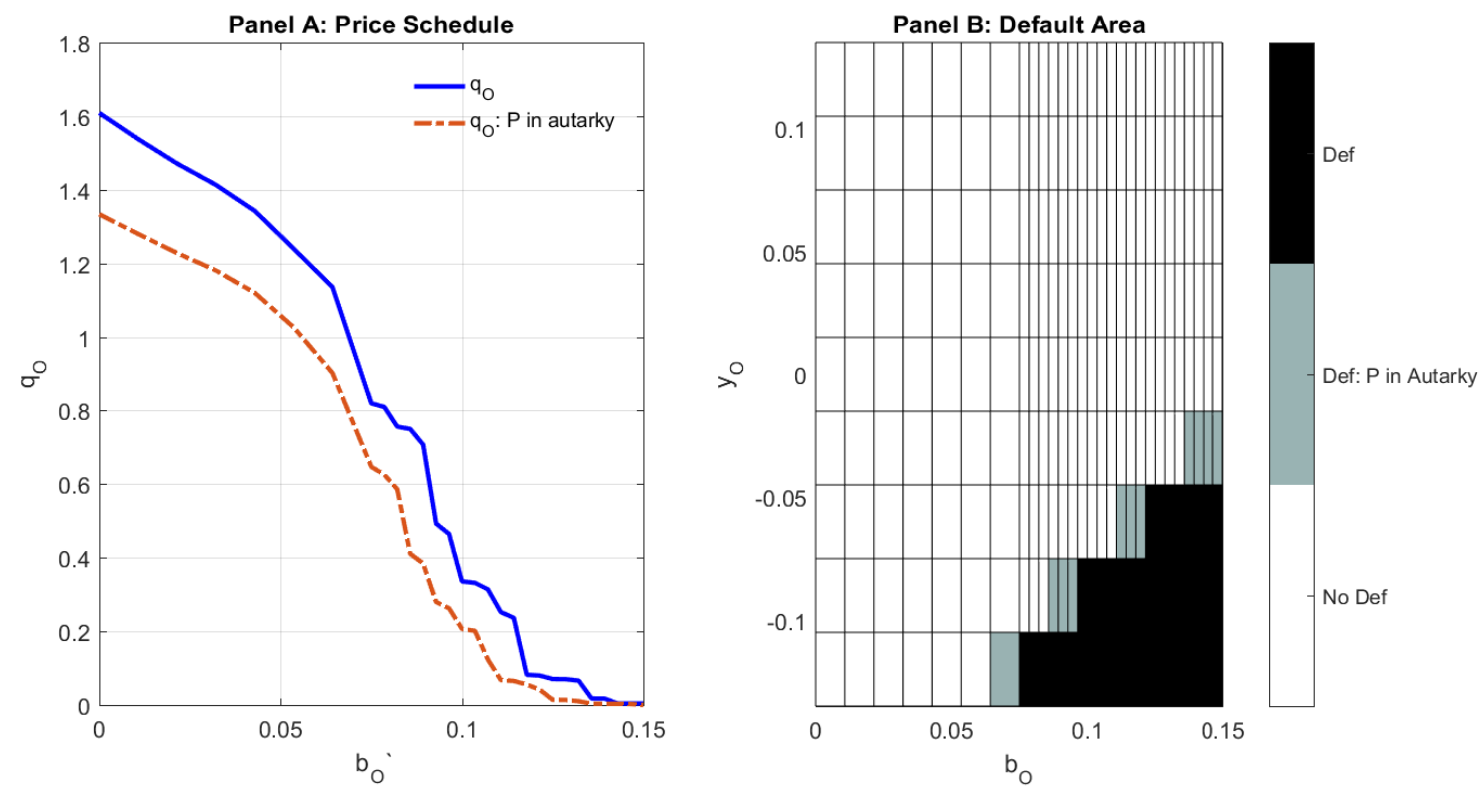

Panel A reports the price function for Outskirt's debt. The blue line corresponds to the case in which Periphery enjoys market access, while the orange line corresponds to the case in which Periphery has no market access. Panel B, plots Outskirt's default set as a function of debt and productivity and for a given productivity and debt levels in the Periphery.

defaults in one country may trigger defaults in the other country. Panel B in Figure 2 plots the default set for Outskirt as a function of Outskirt's debt and productivity. The white area is the no-default area. This is the subset of the state space in which Outskirt never chooses to default. The black area is the default area. This is the subset of the state space in which Outskirt always chooses to default regardless of Periphery's behavior. Finally, the cyan area is the "sovereign default contagion area": this is the subset of the state space in which Outskirt only defaults when Periphery is autarky. 


\subsection{Economic Dynamics}

We simulate our model economy 200 times over 10,000 periods and we compare moments obtained from the model with those in the data. We find, that our model baseline model successfully replicates targeted moments as reported in Panel A of Table 3. Debt-to-GDP ratios obtained from the model are perfectly in line with those in the data. Spreads are also precisely estimated. As reported in Panel B, our model also replicates well a number of key non-targeted moments such as default rates, spreads' volatility, the correlations between spreads and output, and the countercyclicality of the trade balance. To quantify cross-

Table 3. Economic Dynamics

Panel A: Targeted Moments

\begin{tabular}{lccccc}
\hline \hline Moments & Data & Model & Unant. Bailouts & Ant. Bailouts & Central Borrower \\
\hline \hline Mean Debt/GDP O & 0.07 & 0.07 & 0.07 & 0.09 & 0.06 \\
Mean Debt/GDP P & 0.06 & 0.06 & 0.06 & 0.08 & 0.05 \\
Mean Spread O & 99 & 103 & 89 & 285 & 52 \\
Mean Spread P & 204 & 231 & 239 & 300 & 136 \\
\hline \hline
\end{tabular}

Panel B: Non-Targeted Moments

\begin{tabular}{lccccc}
\hline \hline Moments & Data & Model & Unant. Bailouts & Ant. Bailouts & Central Borrower \\
\hline \hline Mean Default Rate 0 & - & $0.8 \%$ & $0.4 \%$ & $1.6 \%$ & $0.4 \%$ \\
Mean Default Rate P & $2.1 \%$ & $1.7 \%$ & $0.2 \%$ & $0.7 \%$ & $1.1 \%$ \\
Bailout Rate O & - & - & $0.3 \%$ & $1.3 \%$ & - \\
Bailout Rate P & - & - & $1.8 \%$ & $2.7 \%$ & - \\
$\sigma_{O}($ spread $)$ & 209 & 229 & 233 & 3052 & 173 \\
$\sigma_{P}($ spread $)$ & 348 & 479 & 504 & 2407 & 268 \\
$\rho_{O}\left(\right.$ spread $\left._{O}, y_{O}\right)$ & -0.14 & -0.17 & -0.15 & -0.36 & -0.20 \\
$\rho_{P}\left(\right.$ spread $\left._{P}, y_{P}\right)$ & -0.45 & -0.37 & -0.40 & -0.40 & -0.42 \\
$\rho_{O}\left(\right.$ nx $\left._{O}, y_{O}\right)$ & -0.02 & -0.05 & -0.05 & -0.20 & -0.09 \\
$\rho_{P}\left(n x_{P}, y_{P}\right)$ & -0.19 & -0.24 & -0.22 & -0.32 & -0.25 \\
Mean Transfer/GDP O & - & - & $0.25 \%$ & $0.72 \%$ & - \\
Mean Transfer/GDP P & - & - & $0.34 \%$ & $0.55 \%$ & - \\
\hline \hline
\end{tabular}

Table 3 reports average moments obtained from model simulation. The model is simulated 200 times for 10,000 periods. The firs column reports moments from the data. The second column reports moments obtained simulating our baseline economy. The third column reports moments obtained when agents do not anticipate the existence of bailouts. The fourth column reports moments obtained when agents anticipate the existence of bailouts. Finally, the last column report moments obtained when the borrowing decision is taken by the central borrower. 
country spillovers we perform a counterfactual experiment. Following Arellano et al. (2017), we solve two versions of the model in which, at turn, we set the endowment of one of the two countries flat and equal to its mean value of 1 . We interpret the difference between spreads obtained in our benchmark model and those obtained in the counterfactual exercise as the contribution of cross-country spillovers to spreads. Results of the counterfactual exercises are reported in Table 4. We find that spreads in Outskirt and Periphery are roughly 25\% lower after we filter out spillovers from Periphery. The magnitude of the cross-country contagion is consistent with empirics. Beirne and Fratzscher (2013), for instance, find that spreads in the euro-area periphery are, on average, $27 \%$ percent lower when spillovers from other euroarea economies are filtered out. These results confirm that our model and our calibration approximate well contagion patterns in the euro-area periphery.

\section{Table 4. Quantifying Cross-Country Spillovers}

\begin{tabular}{lc}
\hline \hline Moments & Model without Spillovers \\
\hline \hline \multicolumn{2}{c}{$P$ 's endowment is fixed } \\
Mean Spread $O$ & 66 \\
Mean Def Rate $O$ & $0.5 \%$ \\
\multicolumn{2}{c}{$O$ 's endowment is fixed } \\
Mean Spread $P$ & 173 \\
Mean Def Rate $P$ & $1.4 \%$ \\
\hline \hline
\end{tabular}

Table 4 reports moments obtained from the counterfactual exercise that shuts down contagion setting, at turn, output flat in each of the two economies.

\section{Normative Analysis}

\subsection{Unanticipated Bailouts}

In this section we quantify the impact of unanticipated bailouts, introduced In Section 4.1, on key economic variables and on agents' welfare. 


\section{Default and Transfer Areas}

In Section 4.1 we defined the "transfer area" as the area of the state space in which both countries gain from unanticipated bailouts. Panel A in Figure 3 plots Periphery's transfer and default areas as a function of Periphery's income and debt while holding Outskirt's income and debt constant. The black-shaded area is the default area. The red-shaded area is the transfer area, that is the area in which a default in Periphery can be avoided with a transfer from Outskirt. Of note, the transfer area lies at the upper margin of the default area. In this area, bailouts are fairly inexpensive as Periphery's incentives to default are limited, suggesting that transfers are typically implemented when they are relatively cheap.

Conditions in Outskirt also influence the size of the transfer area. As shown in figure 7 in the Appendix, the size of the transfer area increases when Outskirt's income is high. This pattern is explained by the fact that Outskirt has more resources to devote to bailouts when it is hit by a positive income shock.

Figure 3. Bailout Area

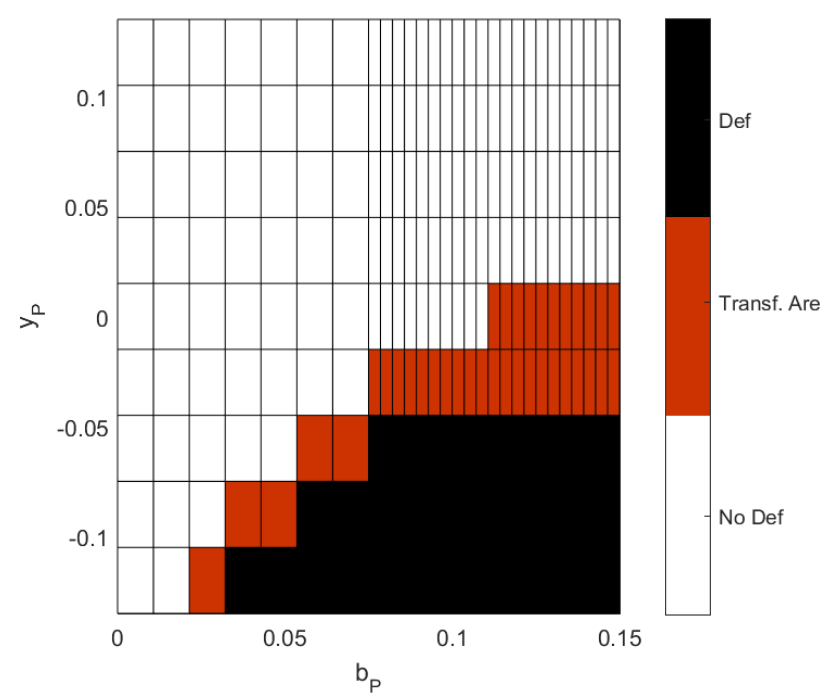

Figure 3 plots the default and transfer areas for the Periphery as a function of Periphery's debt (on the horizontal axis) and output (on the vertical axis) holding Outskirt' debt and output constant. 


\section{Economic Dynamics}

Figure 6 in Appendix 9.4 sheds a light on the way the implementation of bailouts modifies the evolution of key economic variables. The two panels at the top display the evolution of government's borrowings and consumption in Outskirt. Without bailouts (the solid line) government's borrowings fall to zero as the defaults and is excluded from financial markets. With bailouts, Outskirt maintains access to financial market and government borrowings remain positive. Consumption dynamics are also affected by bailouts. The contraction of Outskirt's consumption is stronger with bailouts as the government has to repay its debt when it retains market access. In the subsequent periods, however, consumption is higher in the economy with bailouts as the government can still borrow to finance consumption. Hence, with bailouts, governments give up consumption at the time in which bailouts are implemented in exchange for higher consumption in the future.

The two panels in the middle of Figure 6 display the evolution of government's borrowing and consumption in Periphery. Bailouts mitigate contagion from Outskirt. As a result, Periphery's borrowing terms improve relative to the case without bailouts, allowing the government to borrow more. On net, however, the impact of bailouts on Periphery's consumption is negligible as the cost of supplying the bailout is offset by the improvement of the borrowing rates. Finally, the panels at the bottom of the figure display the average size of the transfer, and the evolution of investors' wealth around bailouts. When bailouts are implemented, investors do not suffer the wealth loss associated with a default. As such, investor's wealth declines less abruptly when bailouts are implemented relative to the case without bailouts.

The impact of bailouts on the long-term moments of our model economy is quantified in Table 3. The third column reports moments obtained when unanticipated bailouts are introduced in the framework. Unanticipated transfer successfully reduce the incidence of defaults as default rates drop from $0.7 \%$ to $0.4 \%$ in Outskirt and from $1.7 \%$ to $0.2 \%$ in Periphery. With the introduction of bailouts, spreads slightly decline in Outskirt and slightly increase in Periphery. The decline of Outskirt's spreads is explained by the fact that bailouts reduce the incidence of defaults in Periphery and, therefore. improve Outskirt's borrowing terms.

The increase of Periphery's spreads is, instead, explained by the fact that Periphery retains market access even when borrowing terms are bad. The remaining moments presented in Table 3 are little changed relative to the benchmark model. This is because agents do not anticipated the existence of bailouts and, therefore, do not modify their borrowing decisions.

In the last two rows of Table 3, we report the average size of bailouts. We find that bailouts 
from Periphery to Outskirt are about $0.25 \%$ of Outskirt's GDP ( $0.27 \%$ of Periphery's GDP). At the same time, bailouts from Outskirt to Periphery are about are about $0.34 \%$ of Periphery's GDP (0.31\% of Outskirt's GDP).

\section{Welfare Analysis}

Welfare gains are computed in terms of consumption equivalent welfare changes $\Delta_{O}^{w}, \Delta_{P}^{w}$, and $\Delta_{L}^{w}$ that make Outskirt, Periphery, and investors indifferent between implementing bailouts or not. ${ }^{18}$ Consumption equivalent welfare changes associated with unanticipated bailouts are reported in the first column of Table 5. We find that unanticipated bailouts improve the welfare of all the agents in the economy. Welfare gains, however, are modest as unanticipated bailouts are infrequent and they do not influence borrowing decisions. Of note, Periphery benefits more than Outskirt from the introduction of bailouts. This is no surprise as Periphery is more frequently the recipient of bailouts. Investors also benefit from bailouts as they avoid welfare losses associated with defaults.

Table 5. Welfare Gains

\begin{tabular}{cccc}
\hline \hline & Unant. Bailouts & Ant. Bailouts & Central Borrower \\
\hline \hline$\Delta_{O}^{w}$ & $0.02 \%$ & $-0.15 \%$ & $0.06 \%$ \\
$\Delta_{P}^{w}$ & $0.08 \%$ & $-0.11 \%$ & $0.12 \%$ \\
$\Delta_{L}^{w}$ & $0.07 \%$ & $0.42 \%$ & $-0.07 \%$ \\
\hline \hline
\end{tabular}

Table 5 reports consumption equivalent welfare changes computed simulating our model 200 times over 10,000 periods. The first column reports welfare gains associated with the introduction of unanticipated bailouts. The second column reports welfare gains associated with anticipated bailouts. Finally, the last column reports welfare gains associated with the institution of the central borrower.

\footnotetext{
$$
\begin{gathered}
W\left(c_{O}^{*}\left(1+\Delta_{O}^{w}\right)\right)=W\left(c_{O}^{* *}\right), \\
V\left(c_{P}^{*}\left(1+\Delta_{P}^{w}\right)\right)=V\left(c_{P}^{* *}\right) . \\
V\left(c_{L}^{*}\left(1+\Delta_{L}^{w}\right)\right)=V\left(c_{L}^{* *}\right) .
\end{gathered}
$$
}

${ }^{18}$ Formally, let $c_{O}^{*}, c_{P}^{*}$, and $c_{L}^{*}$ be the equilibrium consumptions in an economy without bailouts and let $c_{O}^{* *}, c_{P}^{* *}, c_{L}^{* *}$ be the equilibrium consumptions in an economy with bailouts. The consumption equivalent welfare changes $\Delta_{O}^{w}, \Delta_{P}^{w}$, and $\Delta_{L}^{w}$ that make agents indifferent between the two scenarios solve: 


\subsection{Anticipated Bailouts and Moral Hazard}

In the previous sections we assumed that agents are unaware of the existence of bailouts until the moment in which they are implemented. Yet, much of the policy debate around bailouts has revolved around the risk of moral hazard. In particular, several commentators have suggested that the introduction of bailouts may induce them to issue more debt. In this section, we allow agents to anticipate the existence of bailouts and we evaluate whether moral hazard concerns are justified on the basis of our model economy.

The fourth column in Table 3 reports simulated moments for the model economy with anticipated bailouts. We find that anticipated bailouts induce governments to borrow more. The average debt-to-GDP ratio increases from $7 \%$ to $9 \%$ in Outskirt and from $6 \%$ to $7 \%$ in the Periphery. At the same, spreads also increase substantially both in Outskirt and in Periphery. Finally, the incidence of bailouts increases sensibly jumping from $0.3 \%$ to $1.3 \%$ in Outskirt and from $1.8 \%$ to $2.7 \%$ in Periphery. All told, our results indeed confirm that bailouts induce more hazard.

Welfare implications of anticipated bailouts are summarized in the second column of Table $5 .{ }^{19}$ We find that welfare declines in both Outskirt and Periphery as higher debt levels reduce consumption over the cycle in both countries. Investors, instead, unambiguously gain from bailouts as higher government debt translates into higher investors' wealth. We conclude that bailouts are not effective tools to reduce contagion in the sovereign debt market as they induce moral hazard.

\subsection{Central Borrower}

We now turn to the case in which borrowing decisions are taken by a central borrower that maximizes global welfare. Figure 4 compares Core and Periphery's borrowing policies in our benchmark model and in the economy with the central borrower. The central borrower borrows less than individual governments as it understands that additional debt in one country does not only increase default risk in that country, but also affects borrowing terms in the other country.

\footnotetext{
${ }^{19}$ Welfare changes are expressed in consumption equivalent terms as it is the case with unanticipated bailouts.
} 
The last column in Table 3 reports simulated moments for the economy with the central borrower. Relative to the benchmark model, debt-to-GDP ratios are smaller as they decline from $7 \%$ to $6 \%$ in Outskirt and from $6 \%$ to $5 \%$ in Periphery. Central borrower's prudent debt management translates in a sharp decline of spreads and in a lower incidence of defaults.

Figure 4. Policy Functions
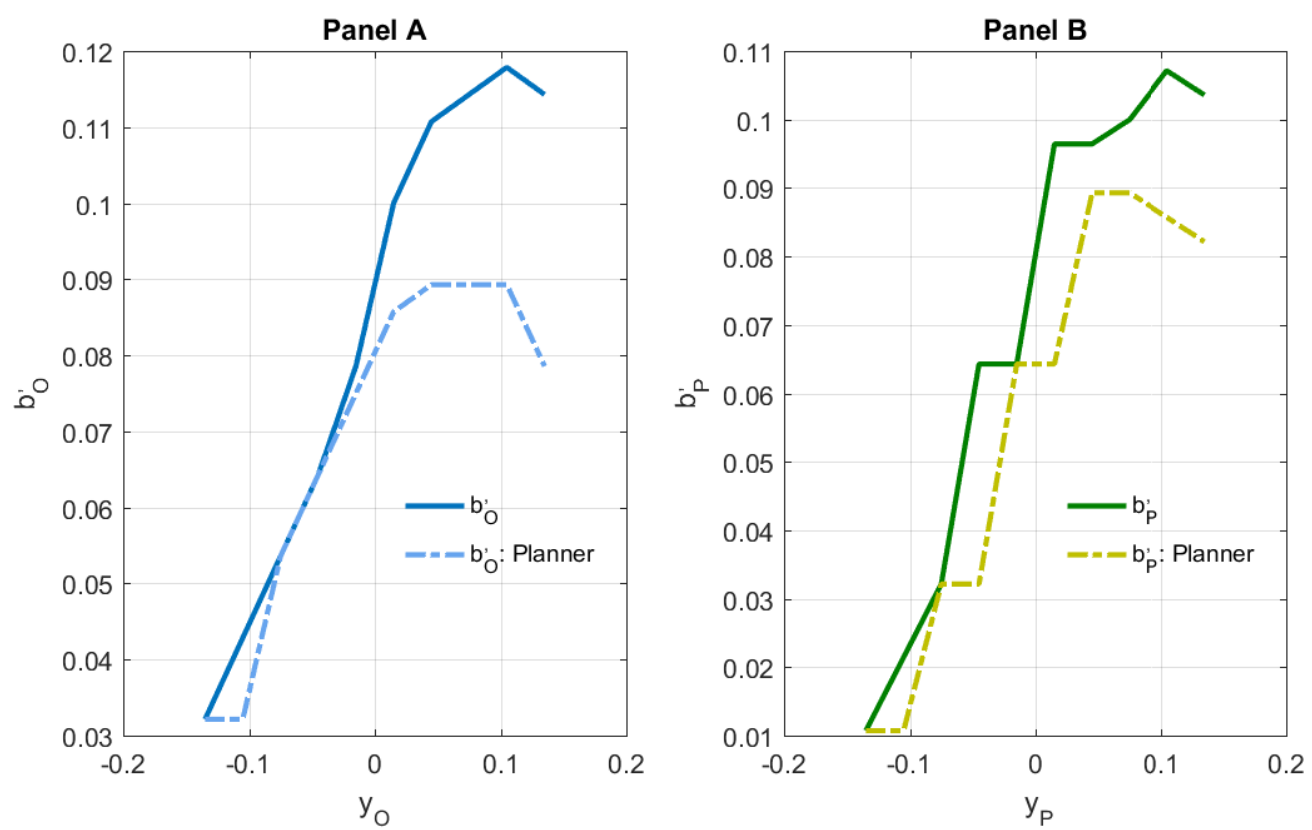

Panel A reports policy functions for the government debt of Outskirt as a function of output $y_{O}$ and given Periphery's output $y_{P}$ and policy $b_{O}^{\prime}$. Panel B reports policy functions for the government debt of Periphery as a function of output $y_{P}$ and given Outskirt's output $y_{P}$ and policy $b_{P}^{\prime}$

The last column of Table 5 reports consumption equivalent welfare changes that make agents indifferent between the benchmark economy and the economy with the central borrower. We find that with the introduction of the central borrower, welfare increases in both Outskirt and Periphery. This is because both countries are less indebted and, over the cycle, can devote more resources to consumption and less resources to the repayment of debt. Investors' welfare, instead, declines as lower government debt translates is lower investors' wealth. 


\subsection{Pigouvian Taxation}

In Section 4.3 we showed that central borrower's allocations can be replicated in a decentralized economy with the introduction of Pigouvian taxes on debt. Table 6 reports summary statistic for the optimal tax rate. First, we look at average tax rates. We find that tax rates should be on average higher in riskier economies such as Periphery. Next, we inspect the correlations between our state variables and the tax rate. We find that the correlation between the tax rate and income (column 2) is negative. This is due to the fact that in bad times excessive borrowing is more likely to trigger defaults and generate cross-country spillovers. We also find that, holding income constant, the conditional correlations between the tax rate and debt levels in that economy and in the other economy are positive (columns 3 and 4). Hence, our quantitative analysis confirms the intuition presented in Section 4.3 that the optimal tax rate should be an increasing function of debt levels in the two countries. Finally, in the last column we look at the correlation between the tax rate and spreads and we find that it is also positive. ${ }^{20}$

Table 6. Pigouvian Taxation

\begin{tabular}{lccccc}
\hline \hline & $\bar{\tau}_{i}$ & $\rho\left(\tau_{i}, y_{i}\right) \mid b_{i}=\bar{b}_{i}$ & $\rho\left(\tau_{i}, b_{i}\right) \mid y_{i}=\bar{y}_{i}$ & $\rho\left(\tau_{i}, b_{j}\right) \mid y_{j}=\bar{y}_{j}$ & $\rho\left(\tau_{i}\right.$, spread $\left._{i}\right)$ \\
\hline \hline$i=$ Outskirt & $2.6 \%$ & -0.37 & 0.29 & 0.19 & 0.08 \\
$i=$ Periphery & $6.7 \%$ & -0.50 & 0.31 & 0.09 & 0.25 \\
\hline \hline
\end{tabular}

Table 6 reports moments for the Pigouvian tax rate that replicates the borrowing policies of the central borrower. Moments are computed simulating the model 200 times over 10,000 periods.

\section{Conclusions}

In this paper we investigate whether cross-country arrangements may improve welfare and reduce cross-country contagion in the sovereign debt market. We build a two-country sovereign default model that allows for cross-country spillovers through a common lender. We calibrate the model to the euro-area Periphery and we show that it matches well key moments

\footnotetext{
${ }^{20}$ Martinez et al. (2015) suggest that rules that set limits to spreads may be preferable to rules that set limits to debt.
} 
in the data and replicates well contagion patterns. We then exploit the model to explore whether a set of policies can reduce contagion and improve welfare.

First, we look at bailouts that are implemented after countries announce a default. We find that bailouts are welfare improving only when they are not anticipated. Whenever agents anticipate their existence, governments issue too much debt, resort to bailouts too frequently, and welfare declines.

Second, we analyze ex-ante policies that are set in place before defaults are announced and aim to reduce spillovers by modifying governments' borrowing incentives. We look in particular at the case in which governments delegate their borrowing decisions to a central borrower. We find that such policy reduces the incidence of defaults, the size of government debt, and increases welfare. Finally, we show that Pigouvian taxes on government debt can successfully replicate central borrower's policies in a decentralized framework.

Our results are relevant for the ongoing debate on the optimal policy response to sovereign stresses in presence of cross-country spillovers. According to our analysis, ex-ante interventions should be preferred to ex-post intervention. Ex-post policies, such as bailouts, may indeed prove counterproductive due to moral hazard. Ex-ante policies, instead, successfully reduce default risk, mitigate contagion, and increase welfare. Admittedly ex-ante policies may be hard to implement. The institution of a central borrower requires that countries delegate their borrowing policy to an external entity giving up some of their sovereignty. The implementation of Pigouvian taxes is also complicated as the optimal tax rate that replicates the central borrower equilibrium is state contingent. Still, our analysis in Section 7.4 provides some guidance to policy makers on how to set the appropriate tax on debt. Taxes should be higher in countries that default more frequently, countercyclical, and increasing in the size of government debt.

In our analysis, we have primarily focused on bailouts and policies that target governments' borrowing and default decisions. The emphasis on such policies is justified by the fact that most of the debate around policy coordination has focused on the harmonization of fiscal rules and the creation of intergovernmental funds providing support to countries in crises. Also interesting, however, are policies that target investors' lending decisions. Investors, indeed, are often responsible for sovereign debt crises as they fuel fiscal profligacy lending too much at too low rates. In that respect, we think that studying policies that target investors, such as financial regulation or forcing lenders to bailout borrowers, is an interesting topic for future research and a natural extension of our work. 


\section{References}

Arellano, Cristina, Yan Bai, and Sandra Lizarazo, "Sovereign Risk Contagion," NBER Working Papers 24031, National Bureau of Economic Research, Inc November 2017.

Azzimonti, Marina and Vincenzo Quadrini, "International Spillovers and 'Ex-ante' Efficient Bailouts," Working Paper 25011, National Bureau of Economic Research September 2018.

Beirne, John and Marcel Fratzscher, "The pricing of sovereign risk and contagion during the European sovereign debt crisis," Journal of International Money and Finance, 2013, 34 (C), 60-82.

Bianchi, Javier, "Efficient Bailouts?," American Economic Review, December 2016, 106 (12), 3607-3659.

_ and Jorge Mondragon, "Rollover Crises and Currency Unions," Technical Report 2018.

Broner, Fernando, Carmen M. Reinhart, and Gaston Gelos, "When in peril, retrench: testing the portfolio channel of contagion," Proceedings, 2004, (jun), 1-34.

Chatterjee, Satyajit and Burcu Eyigungor, "Maturity, Indebtedness, and Default Risk," American Economic Review, October 2012, 102 (6), 2674-2699.

Constancio, V., "Contagion and the European debt crisis," Financial Stability Review, April 2012, (16), 109-121.

Converse, Nathan and Enrico Mallucci, "Preferential Treatment in the Sovereign Debt Market: Evidence from Bond Mutual Funds," Technical Report, Board of Governors of the Federal Reserve System (U.S.) 2019.

de Ferra, Sergio, "External Imbalances, Gross Capital Flows and Sovereign Debt Crises," Technical Report 2017.

- and Federica Romei, "Sovereign Default in a Monetary Union," CEPR Discussion Papers 12976, C.E.P.R. Discussion Papers June 2018.

Forbes, Kristin J., "The Big C: identifying and mitigating contagion," Proceedings Economic Policy Symposium - Jackson Hole, 2012, pp. 23-87.

Goldstein, Itay and Ady Pauzner, "Contagion of self-fulfilling financial crises due to diversification of investment portfolios," Journal of Economic Theory, November 2004, 119 (1), 151-183. 
Gourinchas, Pierre Olivier, Philippe Martin, and Todd Messer, "The Economics of Sovereign Debt, Bailouts and the Eurozone Crisis," Technical Report, University of California, Berkeley 2019.

Hatchondo, Juan Carlos, Leonardo Martinez, and Horacio Sapriza, "Quantitative Properties of Sovereign Default Models: Solution Methods," Review of Economic Dynamics, October 2010, 13 (4), 919-933.

Kyle, Albert S., "Contagion as a Wealth Effect," Journal of Finance, August 2001, 56 (4), 1401-1440.

Lizarazo, Sandra Valentina, "Default risk and risk averse international investors," Journal of International Economics, 2013, 89 (2), 317-330.

Martinez, Leonardo, Francisco Roch, and Juan Hatchondo, "Fiscal rules and the sovereign default premium," Technical Report 2015.

Park, JungJae, "Contagion of Sovereign Default Risk: the Role of Two Financial Frictions," MPRA Paper 55197, University Library of Munich, Germany January 2013.

Pouzo, Demian and Ignacio Presno, "Sovereign Default Risk and Uncertainty Premia," American Economic Journal: Macroeconomics, July 2016, 8 (3), 230-266.

Reinhart, Carmen M. and Kenneth S. Rogoff, This Time Is Different: Eight Centuries of Financial Folly number 8973. In 'Economics Books.', Princeton University Press, 2009.

Tauchen, George and Robert Hussey, "Quadrature-Based Methods for Obtaining Approximate Solutions to Nonlinear Asset Pricing Models," Econometrica, March 1991, 59 (2), 371-96.

Yuan, Kathy, "Asymmetric Price Movements and Borrowing Constraints: A Rational Expectations Equilibrium Model of Crises, Contagion, and Confusion," Journal of Finance, February 2005, 60 (1), 379-411. 


\section{Appendix}

\subsection{Default History}

Figure 5. Countries Entering Default

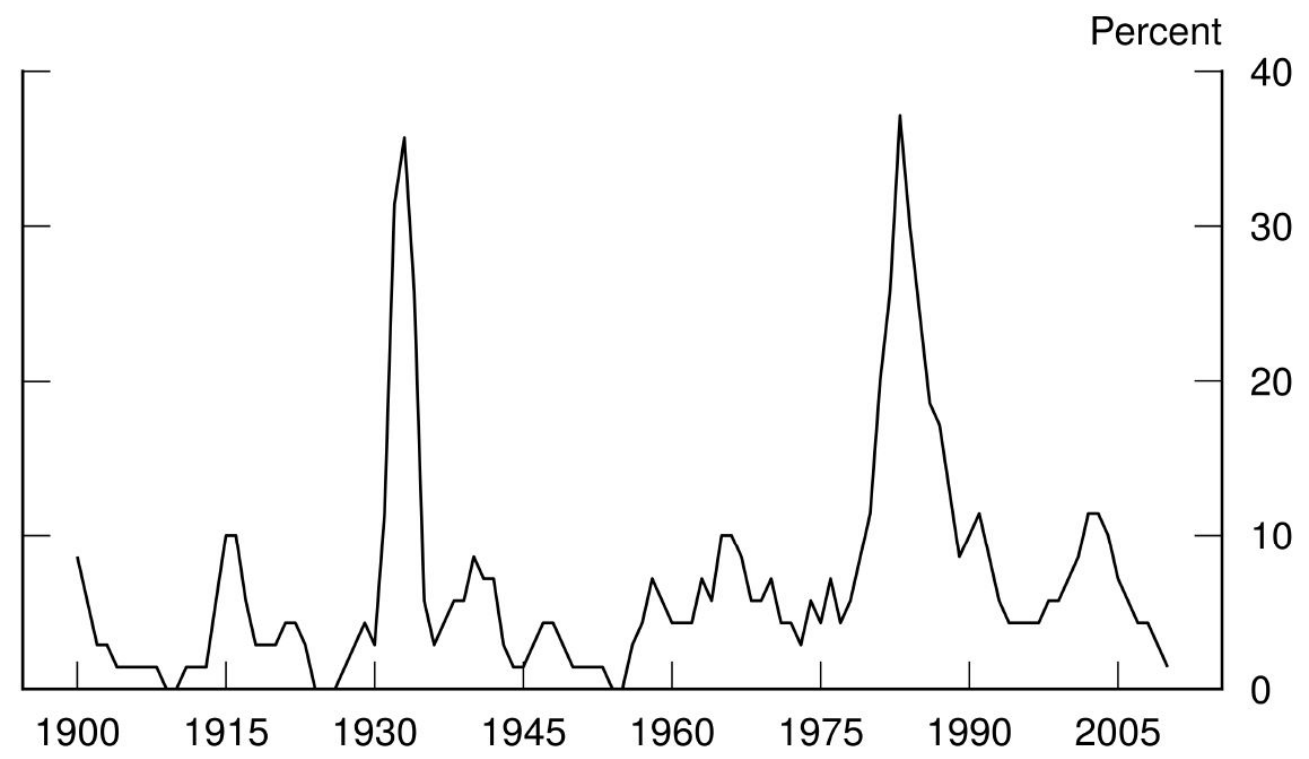

Figure 5 reports the three-year sum of the share of countries entering a new government debt default. Data is taken from Reinhart and Rogoff (2009).

\subsection{Periphery's Government Problem}

\section{Outskirt has Access to Financial Markets and Does Not Default}

Conditional on Outskirt having access to financial markets and not choosing to default, Periphery decides whether to default or not comparing its welfare $V^{n d}$ in the default scenario with its welfare $V^{d}$ in the non-default scenarios. The optimal default decision $d_{P}$ solves

$$
V=\max _{d_{P}}\left\{\left(1-d_{P}\right) V^{n d}+d_{P} V^{d}\right\}
$$


The value function $V^{n d}$ is the solution to the following maximization problem:

$$
\begin{gathered}
V^{n d}\left(y_{O}, y_{P}, b_{O}, b_{P}\right)=\max _{c_{P}, b_{P}^{\prime}} u\left(c_{P}\right)+\beta \mathbb{E}\left[V\left(y_{O}^{\prime}, y_{P}^{\prime}, b_{O}^{\prime}, b_{P}^{\prime}\right)\right] \\
\text { s.t. } c_{P}=A_{P} y_{P}+q_{P} b_{P}^{\prime}-b_{P}, \\
q_{P}=\beta_{L} \frac{E\left[u_{c}\left(c_{L}^{\prime}\right)\left(1-d_{P}\right)\right]}{u_{c}\left(c_{L}\right)} \\
b_{O}^{\prime}=b_{O}^{*}\left(y_{O}, y_{P}, b_{O}, b_{P}\right) . \\
d_{O}=d_{O}^{*}\left(y_{O}, y_{P}, b_{O}, b_{P}\right) .
\end{gathered}
$$

Equation (57) is Periphery's resource constraint. It states that consumption equals production plus net imports from abroad. Equation (58) is the asset pricing equation that is consistent with the maximization problem of international investors. Equation (59) is Outskirt's optimal borrowing decision $b_{O}^{*}\left(y_{O}, y_{P}, b_{O}, b_{P}\right)$ and is included in the set of the constraints as Periphery is the follower and therefore observes Outskirt's borrowing decisions before making its own choices. ${ }^{21}$

If Outskirt chooses to default or if it lacks access to financial markets, the economy suffers from an output cost of exclusion. In this setting, the country's endowment is reduced to $\varphi_{P} y$, where: $\varphi_{P} \equiv 1-\max \left\{0 ; \varphi_{P, 1}+\varphi_{P, 2} A_{P} y\right\}$. Periphery can re-gain access to financial markets with the exogenous probability $\lambda_{P}$.

Periphery's value function, conditional on defaulting or not having access to financial markets, is:

$$
\begin{gathered}
V^{d}\left(y_{O}, y_{P}, b_{O}\right)=u\left(c_{P}\right)+\beta \mathbb{E}\left[\left(1-\lambda_{P}\right) V^{d}\left(y_{O}^{\prime}, y_{P}^{\prime}, b_{O}^{\prime}\right)+\lambda_{P} V\left(y_{O}^{\prime}, y_{P}^{\prime}, b_{O}^{\prime}, 0\right)\right] \\
\text { s.t. } c_{P}=\varphi_{P} A_{P} y,
\end{gathered}
$$

\footnotetext{
${ }^{21}$ Of note in Outskirt problem equations (59) and (60) are replaced by forecasting rules as Outskirt is the "leader".
} 


$$
\begin{aligned}
& b_{O}^{\prime}=b_{O}^{*}\left(y_{O}, y_{P}, b_{O}\right) . \\
& d_{O}=d_{O}^{*}\left(y_{O}, y_{P}, b_{O}\right) .
\end{aligned}
$$

\section{Outskirt is in Autarky or Defaults}

We now turn to the case in which Outskirt is in autarky or it defaults and Periphery is the only country with access to financial markets. In this case, the optimal default decision $d_{\text {only } P}$ is solution to:

$$
V_{\text {only } P}=\max _{d_{\text {only } P}}\left\{\left(1-d_{\text {only } P}\right) V_{\text {only } P}^{n d}+d_{\text {only } P} V_{\text {only } P}^{d}\right\}
$$

where $V_{\mathrm{only} P}^{n d}$ and $V_{\mathrm{only} P}^{d}$ are Periphery's value functions in the non-default and in the default scenarios respectively.

Value function $V_{\text {only } P}^{\text {nd }}$ solves:

$$
\begin{gathered}
V_{\text {only } P}^{n d}\left(y_{O}, y_{P}, b_{P}\right)=\max _{c_{P}, b_{P}^{\prime}} u\left(c_{P}\right)+\beta \mathbb{E}\left[\left(1-\lambda_{O}\right) V_{\text {only } P}\left(y_{O}^{\prime}, y_{P}^{\prime}, b_{P}^{\prime}\right)+\lambda_{O} V\left(y_{O}^{\prime}, y_{P}^{\prime}, 0, b_{P}^{\prime}\right)\right] \\
\text { s.t. } c_{P}=A_{P} y_{P}+q_{\text {only } P} b_{O}^{\prime}-b_{O} \\
q_{\text {only } P}=\beta_{L} \frac{E\left[u_{c}\left(c_{L}^{\prime}\right)\left(1-d_{\text {only } P}\right)\right]}{u_{c}\left(c_{L}\right)} .
\end{gathered}
$$

Where $\lambda_{O}$ is the exogenous probability that Outskirt is readmitted to financial markets. ${ }^{22}$

Finally, we define Periphery's value function $V_{\mathrm{only}}^{d}$, when Periphery defaults and Outskirt is in autarky or has defaulted:

$$
\begin{array}{r}
V_{\text {only } P}^{d}\left(y_{O}, y_{P}\right)=u(c)+\beta \mathbb{E}\left\{\left(1-\lambda_{O}\right)\left[\left(1-\lambda_{P}\right) V_{\text {only } P}^{d}\left(y_{O}^{\prime}, y_{P}^{\prime}\right)+\lambda_{P} V_{\text {only } P}\left(y_{O}^{\prime}, y_{P}^{\prime}, 0\right)\right]\right. \\
\left.+\lambda_{O}\left[\left(1-\lambda_{P}\right) V^{d}\left(y_{O}^{\prime}, y_{P}^{\prime}, 0\right)+\lambda_{P} V\left(y_{O}^{\prime}, y_{P}^{\prime}, 0,0\right)\right]\right\}
\end{array}
$$

\footnotetext{
${ }^{22}$ Note that Outskirt's optimal borrowing policy is now excluded from the set of constraints as Outskirt cannot borrow from investors in autarky.
} 


$$
\text { s.t. } c=\varphi A_{P} y \text {. }
$$

\subsection{Centralized Borrower Problem}

$G$ is the solution to the maximization problem of the global borrower when both Outskirt and Periphery have access to financial markets:

$$
\begin{aligned}
& G^{n d}\left(y_{O}, y_{P}, b_{O}, b_{P}\right)=\max _{c_{O}, b_{O}^{\prime}, c_{P}, b_{P}^{\prime}} u\left(c_{O}\right)+u\left(c_{P}\right)+\beta \mathbb{E}\left\{\left(1-d_{O}\right)\left(1-d_{P}\right) G\left(y_{O}^{\prime}, y_{P}^{\prime}, b_{O}^{\prime}, b_{P}^{\prime}\right)\right. \\
& +d_{O}\left(1-d_{P}\right) G_{\text {only } P}\left(y_{O}^{\prime}, y_{P}^{\prime}, b_{P}^{\prime}\right)+\left(1-d_{O}\right) d_{P} G_{\text {only } O}\left(y_{O}^{\prime}, y_{P}^{\prime}, b_{O}^{\prime}\right) \\
& \left.+d_{O} d_{P} G^{d}\left(y_{O}^{\prime}, y_{P}^{\prime}\right)\right\} \\
& \text { s.t. } c_{O}=A_{O} y_{O}+q_{O} b_{O}^{\prime}-b_{O} \text {, } \\
& \text { s.t. } c_{P}=A_{P} y_{P}+q_{P} b_{P}^{\prime}-b_{P} \text {, } \\
& q_{O}=\beta_{L} \frac{E\left[u_{c}\left(c_{L}^{\prime}\right)\left(1-d_{O}\right)\right]}{u_{c}\left(c_{L}\right)}, \\
& q_{P}=\beta_{L} \frac{E\left[u_{c}\left(c_{L}^{\prime}\right)\left(1-d_{P}\right)\right]}{u_{c}\left(c_{L}\right)} .
\end{aligned}
$$

$G_{\text {only } P}$ is the solution to the maximization problem of the global borrower when Outskirt is in autarky:

$$
\begin{array}{r}
G_{\text {only } P}\left(y_{O}, y_{P}, b_{P}\right)=\max _{c_{O}, c_{P}, b_{P}^{\prime}} u\left(c_{O}\right)+u\left(c_{P}\right)+\beta \mathbb{E}\left\{( 1 - \lambda _ { O } ) \left[\left(1-d_{P}\right) G_{\text {only } P}\left(y_{O}^{\prime}, y_{P}^{\prime}, b_{P}^{\prime}\right)\right.\right. \\
\left.+d_{P} G^{d}\left(y_{O}^{\prime}, y_{P}^{\prime}\right)\right]+\lambda_{O}\left[\left(1-d_{P}\right) G\left(y_{O}^{\prime}, y_{P}^{\prime}, 0, b_{P}^{\prime}\right)\right. \\
\left.\left.+d_{P} G_{\text {only } O}\left(y_{O}^{\prime}, y_{P}^{\prime}, 0\right)\right]\right\}
\end{array}
$$

s.t. $c_{O}=\varphi A_{O} y_{O}$,

$$
c_{P}=A_{P} y_{P}+q_{P} b_{P}^{\prime}-b_{P},
$$




$$
q_{P}=\beta_{L} \frac{E\left[u_{c}\left(c_{L}^{\prime}\right)\left(1-d_{P}\right)\right]}{u_{c}\left(c_{L}\right)}
$$

$G_{\text {only }}$ is the solution to the maximization problem of the global borrower when Periphery is in autarky:

$$
\begin{array}{r}
G_{\text {only } O}\left(y_{O}, y_{P}, b_{O}\right)=\max _{c_{O}, b_{O}^{\prime}, c_{P}} u\left(c_{O}\right)+u\left(c_{P}\right)+\beta \mathbb{E}\left\{( 1 - \lambda _ { P } ) \left[\left(1-d_{O}\right) G_{\text {only } O}\left(y_{O}^{\prime}, y_{P}^{\prime}, b_{O}^{\prime}\right)\right.\right. \\
\left.+d_{O} G^{d}\left(y_{O}^{\prime}, y_{P}^{\prime}\right)\right]+\lambda_{P}\left[\left(1-d_{O}\right) G\left(y_{O}^{\prime}, y_{P}^{\prime}, b_{O}^{\prime}, 0\right)\right. \\
\left.\left.+d_{0} G_{\text {only } P}\left(y_{O}^{\prime}, y_{P}^{\prime}, 0\right)\right]\right\}
\end{array}
$$

s.t. $c_{O}=A_{O} y_{O}+q_{O} b_{O}^{\prime}-b_{O}$,

s.t. $c_{P}=\varphi A_{P} y_{P}$,

$$
q_{O}=\beta_{L} \frac{E\left[u_{c}\left(c_{L}^{\prime}\right)\left(1-d_{O}\right)\right]}{u_{c}\left(c_{L}\right)} .
$$

Finally $G^{d}$ is the solution when both Outskirt and Periphery are in autarky

$$
\begin{array}{r}
G^{d}\left(y_{O}, y_{P}\right)=u\left(c_{O}\right)+u\left(c_{P}\right)+\beta \mathbb{E}\left[\left(1-\lambda_{O}\right)\left(1-\lambda_{P}\right) G^{d}\left(y_{O}^{\prime}, y_{P}^{\prime}\right)\right. \\
\lambda_{O}\left(1-\lambda_{P}\right) G_{\text {only } O}\left(y_{O}^{\prime}, y_{P}^{\prime}, 0\right)+\left(1-\lambda_{O}\right) \lambda_{P} G_{\text {only } P}\left(y_{O}^{\prime}, y_{P}^{\prime}, 0\right)+ \\
\left.\lambda_{O} \lambda_{P} G\left(y_{O}^{\prime}, y_{P}^{\prime}, 0,0\right)\right]
\end{array}
$$

s.t. $c_{O}=\varphi A_{O} y_{O}$,

s.t. $c_{P}=\varphi A_{P} y_{P}$. 


\subsection{Economic Dynamics around Defaults and Bailouts}

Figure 6. Dynamics around Bailouts
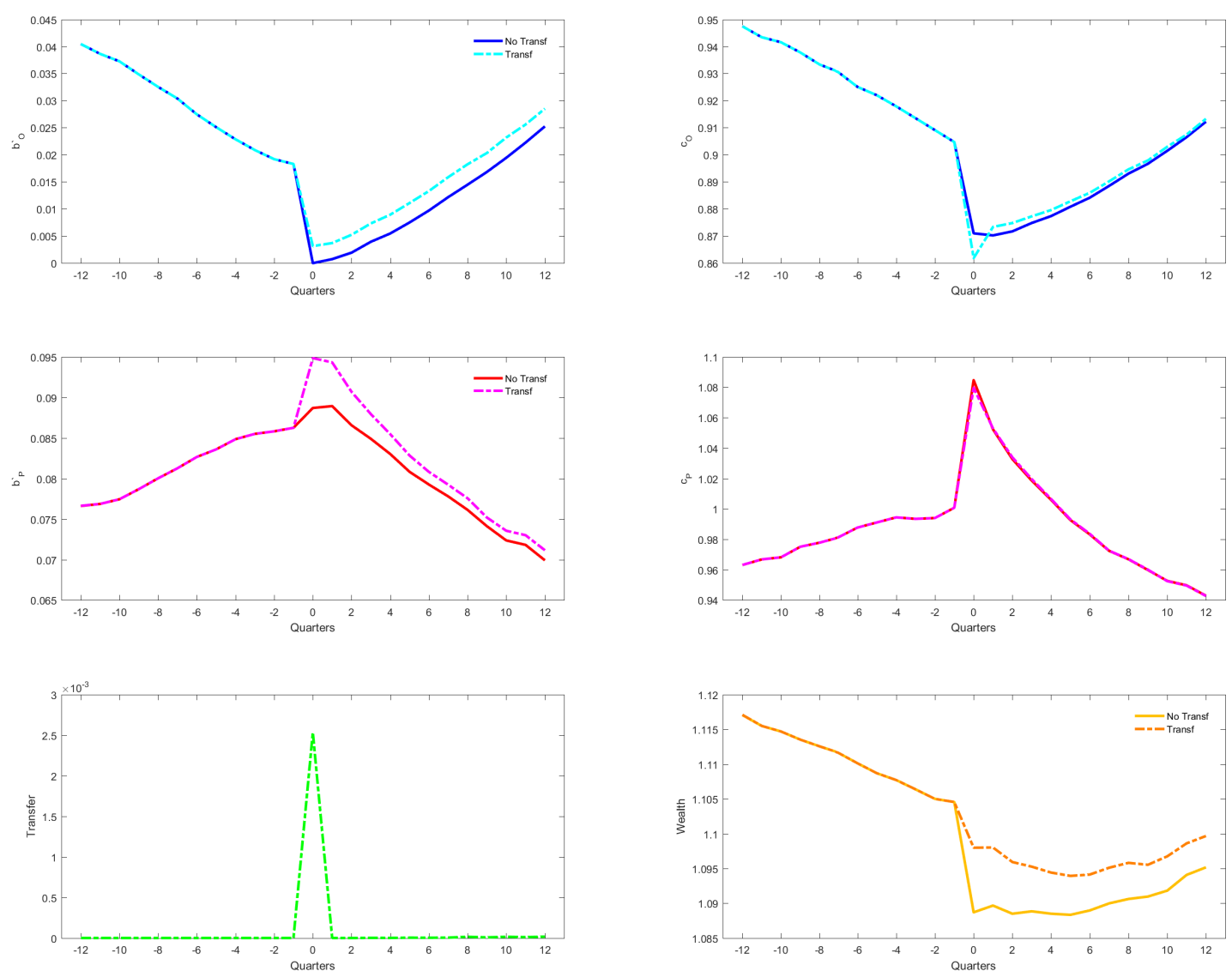

Figure 6 compares the average evolution of Outskirt and Periphery's consumption and borrowings, as well as investors' wealth in an economy with bailouts and in an economy without them. Simulations are obtained running our model 200 times for 10,000 periods and computing the average evolution of our key economic variables in the 12 years before and after a default in Outskirt that can be avoided with a bailout from Periphery. The top panel reports the evolution of government's borrowings and consumption in Outskirt. The middle panel reports the evolution of government's borrowings and consumption in Periphery. The bottom panel reports the transfer from Periphery to Outskirt, and the evolution of investors' wealth around bailouts. 


\subsection{Sensitivity Analysis}

We evaluate how a number of key moments change when we modify our assumption about the exogenous income of investors $y_{L}$. Results are reported in Table 7 . We find that changing our assumptions on $y_{L}$ has a negligible impact on most moments with the exception default rates and spreads especially in the Periphery. When investors' income is higher, the incidence defaults increases and so do spreads. This is due to the fact that richer investors are less averse to risk. Hence, when $y_{L}$ is high, investors are willing to purchase large quantities of government debt. When, instead, $y_{L}$ is low, debt levels decline.

Table 7. Sensitivity Analysis

\begin{tabular}{|c|c|c|}
\hline Moments & $y_{L}=0.8$ & $y_{L}=1.2$ \\
\hline Mean Debt/GDP O & 0.07 & 0.08 \\
\hline Mean Debt/GDP P & 0.06 & 0.07 \\
\hline Mean Spread O & 95 & 98 \\
\hline Mean Spread P & 218 & 257 \\
\hline Moments & $y_{L}=0.8$ & $y_{L}=1.2$ \\
\hline Mean Default Rate 0 & 0.7 & $0.7 \%$ \\
\hline Mean Default Rate P & $1.6 \%$ & $1.9 \%$ \\
\hline$\sigma_{O}($ spread $)$ & 245 & 249 \\
\hline$\sigma_{P}($ spread $)$ & 459 & 483 \\
\hline$\rho_{O}\left(\right.$ spread $\left._{O}, y_{O}\right)$ & -0.16 & -0.16 \\
\hline$\rho_{P}\left(\operatorname{spread}_{P}, y_{P}\right)$ & -0.38 & -0.34 \\
\hline$\rho_{O}\left(n x_{O}, y_{O}\right)$ & -0.05 & -0.05 \\
\hline$\rho_{P}\left(n x_{P}, y_{P}\right)$ & -0.22 & -0.23 \\
\hline
\end{tabular}

Table 7 reports average moments obtained from model simulation. The model is simulated 200 times for 10,000 periods. The first column reports moments obtained setting the exogenous income of the lender equal to 0.8 . In the second column we reports moments obtained setting the exogenous income of the lender equal to 1.2

Next, we attempt to establish how the intensity of cross-country spillovers changes when we modify investors' endowment. Table 8 reports the results obtained repeating the counterfactual exercise introduced in Section 6.2 when we set $y_{L}=0.8$ (first column) and $y_{L}=1.2$ (second column). Once again, we interpret the difference in spreads between Tables 7 and 8 as the contribution of cross-country spillovers to spreads. We find that as $y_{L}$ increases, the intensity of contagion becomes smaller. When the exogenous income $y_{L}$ is small, the 
contribution of cross-country spillovers to the spreads is about $30 \%$ in both country. Such contribution declines to roughly $14 \%$ in Outskirt and $9 \%$ in Periphery when investors' income increases to 1.2. These results are consistent with investors becoming less risk averse as they get richer.

Table 8. Quantifying Cross-Country Spillovers

\begin{tabular}{lcc}
\hline \hline Moments & $y_{L}=0.8$ & $y_{L}=1.2$ \\
\hline \hline \multicolumn{2}{c}{$P$ 's endowment is fixed } \\
Mean Spread $O$ & 67 & 84 \\
Mean Def Rate $O$ & $0.4 \%$ & 0.5 \\
\multicolumn{2}{c}{$O$ 's endowment is fixed } \\
Mean Spread $P$ & 146 & 227 \\
Mean Def Rate $P$ & $1.2 \%$ & 1.6 \\
\hline \hline
\end{tabular}

Table 8 reports moments obtained from the counterfactual exercise that shuts down contagion setting, at turn, output flat in each of the two economies. 


\subsection{Transfer Area}

Figure 7. Bailout Area

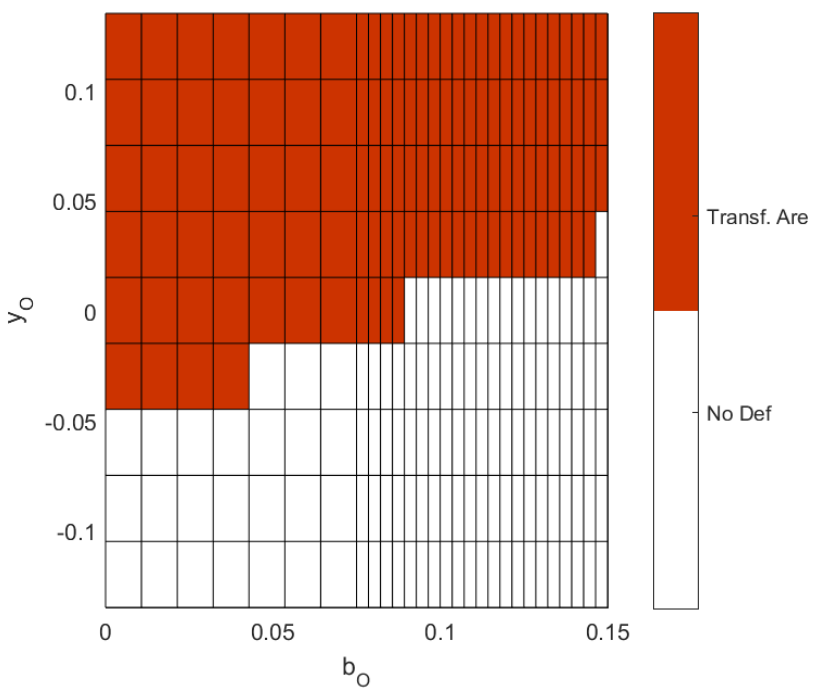

Figure 7 plots the transfer area of Periphery as a function of Outskirt's debt (on the horizontal axis) and output (on the vertical axis) holding Periphery' debt and output constant. The transfer area is increasing in Outskirt's income and decreasing in Outskirt's debt.

\subsection{Solution Algorithm}

Following Hatchondo et al. (2010), the equilibrium is found iterating the finite-horizon version of the model backward until convergence. In the terminal period, financial markets are closed, as there is no need to transfer resources across time:

In the final period:

- Discretize income processes $y_{O}$ and $y_{P}$.

- Set up the vector of state space $\Omega=\left\{y_{O} \times y_{P} \times b_{O} \times b_{P}\right\}$ defining the state space

- Compute Outskirt and Periphery's value functions in the following four scenarios (note that, in the final period, value functions and utility functions coincide as there is no continuation value): 
1. Both countries have market access and decide not to default.

2. Only Outskirt has market access because Periphery has either decided to default or lacks market access.

3. Only Periphery has market access because Outskirt has either decided to default or lacks market access.

4. Neither Outskirt or Periphery have market access as they have defaulted of they lack market access.

- Determine Outskirt and Periphery's default policies comparing the relevant utility functions.

- Given Outskirt and Periphery's default policy, compute the utility function of international investors and their marginal utility.

In every other period:

1. Discretize income processes $y_{O}$ and $y_{P}$ and determine the associated transition matrix $Y$ using the quadrature method for a multivariate normal distribution described in Tauchen and Hussey (1991)

2. Set up the grid of states $\left\{y_{O}, y_{P}, b_{O}, b_{P}\right\}$ and choices $\left\{b_{O}^{\prime}, b_{P}^{\prime}\right\}$

3. Construct expected value functions, expected marginal utility of investors, and expected default probabilities using value functions, marginal utilities, and default policies in $t+1$.

4. Solve Periphery's problem taking future default decisions as given and for every possible Outskirt's borrowing strategy $b_{O}^{\prime}$ :

(a) Case 1: Both Periphery and Outskirt have access to financial market and neither country defaults.

- Determine prices:

- Guess the denominators of the price function for debt (equation 58) and use investors' expected marginal utility of consumption as a numerator.

- For each possible choice, compute investors' consumption and marginal utility in each point of the grid and update the guesses for the denominator (note that at this stage we are not solving the maximization problem, 
but simply computing Outskirt and Periphery's consumption on each state and for each possible choice).

- Iterate till the price for Outskirt and Periphery's government bonds converge.

- Compute Periphery's utility function and construct Periphery's Bellman equation (equation 56) using the expected value function derived from $t+1$.

- Determine Periphery's optimal borrowing policy $b_{P}^{* *}$ and value $V$ function contingent on the borrowing choices of Outskirt.

(b) Case 2: Both Periphery and Outskirt have access to financial market and Outskirt decides to default (this case is equivalent to the case in which Periphery has market access and Outskirt is in autarky).

- Determine prices as in Case 1

- Compute Periphery's utility function and construct Periphery's Bellman equation (equation 65) using the expected value function derived from $t+1$. The continuation value allows for Outskirt to regain market access with probability $\lambda_{O}$.

- Determine Periphery's optimal borrowing policy $b_{P, \text { only } P}^{\prime *}$ and value function $V_{\text {onlyP }}$ contingent on Outskirt not having market access.

(c) Case 3: Both Periphery and Outskirt have access to financial market and Periphery decides to default (the case in which Outskirt has market access and Periphery is in autarky is exactly the same).

- The price of Periphery's debt is equal to zero.

- Compute Periphery's utility function and construct Periphery's Bellman equation (equation 61) using the expected value function derived from $t+1$. The present utility only depends on income as Periphery defaults (or has no market access). The continuation value allows for Periphery to regain market access with probability $\lambda_{P}$.

- Periphery does not issue debt, so the only possible borrowing choice is $b_{P, \text { onlyO }}^{*}=$ 0 and the associated value function is $V^{d}$.

(d) Case 4: Both Periphery and Outskirt default (the case in which both Outskirt and Periphery are in autarky and the case in which Periphery is the only country with market access and it defaults is exactly the same).

- The price of Periphery's debt is flat and equal to zero. 
- Compute Periphery's utility function and construct Periphery's Bellman equation (equation 69) using the expected value function derived from $t+1$. The present utility only depends on income as Periphery defaults (or has no market access). The continuation value allows for Periphery to regain market access with probability $\lambda_{P}$ and Outskirt to regain access with probability $\lambda_{O}$.

- Periphery does not issue debt, so the only possible borrowing choice is $b_{P}^{\prime *}=0$ and the associated value function is $V_{\text {all }}^{d} \cdot{ }^{23}$

5. Solve Outskirt's problem taking future default decisions as given and given Periphery' strategies derived in the previous step:

(a) Case 1: Both Periphery and Outskirt have access to financial market and neither country defaults.

- Determine debt price (equation 12) as in Periphery's problem.

- Compute Outskirt's utility function and construct the associated Bellman equation (equation 10) using the expected value functions derived from $t+1$.

- Impose that $b_{P}^{\prime}=b_{P}^{*}$ and derive the optimal borrowing rule $b_{O}^{* *}$ and the associated value function $W$.

(b) Case 2: Both Periphery and Outskirt have access to financial market and Outskirt decides to default.

- Determine debt prices as in Periphery's problem.

- Compute Outskirt's utility function and construct the associated Bellman equation (equation 15)using the expected value functions derived from $t+1$.

- Impose that $b_{P}^{\prime}=b_{o n l y P}^{* *}$ and derive the optimal borrowing rule $b_{O, \text { onlyP }}^{*}$ and the associated value function $W^{d}$.

(c) Case 3: Both Periphery and Outskirt have access to financial market and Periphery decides to default.

- Determine debt prices as in Periphery's problem.

- Compute Outskirt's utility function and construct the associated Bellman equation (equation 19) using the expected value functions derived from $t+1$.

- Impose that $b_{P}^{\prime}=0$ and derive the optimal borrowing rule $b_{O, \text { onlyO }}^{*}$ and the associated value function $W_{O \text {,onlyO }}$

(d) Case 4: Both Periphery and Outskirt default.

\footnotetext{
${ }^{23}$ Note that we use the notation $V_{\text {only } P}^{*}$ as the value function when both defaults is the same as the value function when only $\mathrm{P}$ has market access and it defaults.
} 
- Determine debt prices as in Periphery's problem.

- Compute Outskirt's utility function and construct the associated Bellman equation (equation 23) using the expected value functions derived from $t+1$.

- Impose that $b_{P}^{\prime}=0$ and derive the optimal borrowing rule $b_{O}^{*}$ and the associated value function $V_{\text {all }}^{d}$.

6. Plug Outskirt's policy functions in Periphery's policy functions and value functions derived in step 4 to obtain equilibrium policies (policies derived in 4 are conditional on Outskirt's borrowing policies).

7. Compute Periphery's optimal default policies conditional on Outskirt having market access comparing Periphery's equilibrium value functions obtained from Case 1 and Case 3.

8. Compute Periphery's optimal default policies conditional on Outskirt being in autarky comparing Periphery's equilibrium value functions obtained from Case 2 and Case 4.

9. Compute Outskirt's equilibrium default policy comparing the the relevant value function in every state given Periphery's default policy.

10. Plug Outskirt's equilibrium default policy in Periphery's default policy to obtain Periphery's equilibrium default policy.

11. Determine investors' consumption given Outskirt and Periphery's default and borrowing policies and the associated prices of government debt.

12. Repeat step 2-11 till policy functions, value function, default decisions, and government debt prices converge. 